\title{
THE KNOWER AND THE KNOWN: THE NATURE OF KNOWLEDGE IN RESEARCH ON TEACHING*‡
}

\author{
Gary D Fenstermacher \\ University of Arizona, Tucson
}

\section{INTRODUCTION}

This chapter is a review of conceptions of knowledge as they appear in selected bodies of research on teaching. Writing as a philosopher of education, my interest is in how notions of knowledge are used and analyzed in a number of research programs that study teachers and their teaching. Of particular interest is the growing research literature on the knowledge that teachers generate as a result of their experience as teachers, in contrast to the knowledge of teaching that is generated by those who specialize in research on teaching. This distinction, as will become apparent, is one that divides more conventional scientific approaches to the study of teaching from what might be thought of as alternative approaches.

A number of good reviews of the teacher knowledge literature are available elsewhere. Though these tend to be confined to a particular genre of teacher knowledge research, they are thoughtful, probing and helpful. Among them are Kathy Carter's (1990) chapter in the Handbook of Research on Teacher Education, Alan Tom and Linda Valli's (1990) philosophically grounded review of professional knowledge; and Peter Grimmett and Allan MacKinnon's (1992) extensive analysis of craft conceptions of teaching in a previous volume in this series. What distinguishes the present review from these others is that it seeks to be fairly inclusive of the teacher knowledge literature, though restrictive in its analytical categories. I shall examine a number of different research programs that either explicitly purport to be about teacher knowledge or that expand what is known about teaching. The examination, however, will be restricted to the

\footnotetext{
*A significant portion of this chapter is based on prior work done in collaboration with Virginia Richardson. This work resulted in an earlier, substantially different version of this chapter, presented at a conference on teacher knowledge in Tel Aviv, Israel, in June, 1993. Frederick Ellett, Peter Grimmett, Hugh Munby, Nel Noddings, Robert Orton, and Denis Phillips, offered extended and extremely helpful critiques of this chapter, for which I am deeply indebted. For the many errors of fact and interpretation from which they have spared me, I thank them. They bear no responsibility for what remains. Peter P. Grimmett and Lee S. Shulman were the editorial consultants for this chapter, a role they performed with diligence and grace.

¥This text is the manuscript version of the following published chapter: Gary D Fenstermacher (1994), The Knower and the Known: The Nature of Knowledge in Research on Teaching, in Linda Darling Hammond (Ed.), Review of Research in Education, 20 (pp. 3-56), Washington, DC:: American Educational Research Association. The text of this manuscript version may not be identical to the published piece; the pagination will definitely be different..
} 
epistemological aspects of these research programs. By epistemological aspects, I mean those features of the research that assert or imply notions about the nature of knowledge: What forms it takes, how it is justified, how it is differentiated from such related concepts as belief and opinion, and how it figures into different conceptions of science and human reasoning.

One may with reason wonder whether any benefit is to be gained by working one's way through the epistemological underbrush while traversing the teacher knowledge terrain. The value is in having a better understanding of what is involved in researchers' claims to know something about teaching as well as their claims that teachers know some things about teaching. These claims can and do become the basis for educational policy, even when our acceptance of them is more a matter of ideological tilt or cosmetic appeal than of clear-headed analysis and reasoned deliberation. Take, for example, the frequently lauded "knowledge base" for teaching.

In the United States, many members of the policy making community are embracing a view of teacher knowledge and skill that represents a limited epistemological perspective on what teachers should know and be able to do. This perspective is classified in this review as the Formal perspective. It is grounded in a conception of the social and behavioral sciences that are themselves constructed isomorphically to the physical sciences. It is from this perspective that we have built the much-vaunted "knowledge base" for teaching. It is this knowledge base that in turn gives rise to such policy initiatives as national certification for teachers, accountability and performance assessment in teaching, research-based programs of teacher education as well as researchbased designs for the accreditation of teacher education, and some (though not all) of the current initiatives in the development of subject field, grade level, and state level standards for student learning.

If our educational policies are defended on the basis of their foundations in science, and science in turn rests on epistemology for an understanding of the nature and scope of its knowledge claims, then epistemology is crucial. Suppose it turned out that the epistemology was faulty, or that it was more limited and constrained than previously thought, or that it was but one among a number of possible epistemologies, or that it was the wrong epistemology for the nature of the inquiry. What then? If educational policy is grounded in weak or erroneous assumptions about the nature of knowledge, there is a high likelihood that it will fail to address the problems and aspirations of education in positive and ameliorative ways.

This review is an occasion to reconsider the epistemological character of what is and can be known by and about teachers and about teaching. It begins, in part II, with a description of a number of different research programs in the 
study of teaching. These programs are grouped in ways that open useful avenues into issues of epistemology. After examining the research literature, we turn, in part III, to an analysis of its epistemological structure. Of particular interest here is the kind of knowledge that researchers and teachers claim to have, and how we know they have it. This inquiry into the nature of teacher knowledge raises issues beyond the confines of epistemology, leading us to look, in part IV, at conceptions of science that undergird the various forms of teacher knowledge research. The inquiry into science shows both promise and problems for gaining firmer epistemological ground. The problems lead to a search for other ways of establishing the knowledge that researchers claim they or the teachers they study have. Part V introduces the topic of practical reasoning in teaching, with an eye toward recasting portions of the teacher knowledge research as research on teacher reasoning. The chapter concludes with an assessment of what needs to be done to continue the high potential of newer research programs for the study of teacher knowledge.

Throughout this review consideration is given to the knower and the known in teacher knowledge research. Questions will be raised about who is the knower, and what it is that the knower knows. Is the knower the researcher (typically thought of as a university professor), or the teacher, or both researcher and teacher? Is whatever it is that is known known only by the researcher, only the teacher, or by both? If both teacher and researcher are considered seekers and producers of knowledge, how are they different with respect to the research endeavor? These are the questions that come to mind as one pursues the several literatures on the subject of teacher knowledge. We turn now to these literatures, examining them in ways that address these questions about the knower and the known.

\section{AN OVERVIEW OF THE TEACHER KNOWLEDGE LITERATURE}

After struggling with a number of devices for arraying the literature in ways that would facilitate epistemological scrutiny, a series of questions offered the best approach to setting forth the relevant research. There are four questions, as follows:
A. What is known about effective teaching?
B. What do teachers know?
C. What knowledge is essential for teaching?
D. Who produces knowledge about teaching?

These four questions do not exhaust the research studies dealing with knowledge in teaching. Instead they prompt consideration of those research initiatives that raise substantial epistemological questions. Hence many studies that, on their 
face, appear relevant to the topic are missing from this review. That is because the point of the review is to grapple with research that raises substantial, and on occasion, controversial issues in epistemology. Thus the work included here is foundational to a particular research program, it is exemplary of that program, or it is a very recent and extensive study within a particular approach to research on teaching.

Some foreshadowing of the answers to these four questions will prove helpful in following the overview. The question, What is known about effective teaching? permits us to address the concept of knowledge as it appears in standard or conventional behavioral science research. In this chapter, this concept of knowledge is called Formal knowledge, and it is abbreviated TK/F (Teacher Knowledge: Formal). The process-product studies of teaching are perhaps the most well-known instance of this form of knowledge. The second question, What do teachers know? points to research that seeks to understand what teachers know as a result of their experience as teachers. Quite a few kinds of knowledge are suggested in answer to this question, including practical, personal practical, situated, local, relational, and tacit. These types of knowledge are designated TK/P, for "Teacher Knowledge: Practical."

These first two questions encompass the epistemological types of knowledge suggested in the research literature, but they do not exhaust the range of the literature itself. The third question, What knowledge is essential for teaching? directs us to the research program of Lee Shulman and his colleagues. It will be argued that Shulman's work does not introduce types of knowledge different from those represented in answers to the first two questions, but rather seeks to show what forms and types of knowledge are required in order to teach competently. The fourth question, Who produces

knowledge about teaching? permits us to address the difference between knowledge generated by university-based researchers and that generated by practicing teachers. The work of Marilyn Cochran-Smith and Susan Lytle is quite prominent in this category, and thus serves as the exemplar in addressing the fourth question.

Before turning to the specific questions, it is necessary to attend briefly to matters of definition. In this review I frequently refer to research programs. This expression typically refers to Imre Lakatos's (1970) notion of a broad group of research studies united by common methodological rules. In this review, the expression refers to the work of certain researchers, and the studies based on the work of these researchers. Thus, for example, I will refer to Michael Connelly and Jean Clandinin's work on personal practical knowledge as a research program, and in doing so I mean to include within the category their own work on this concept as well as the work of collaborators and like-minded colleagues. Hence all research studies that use Connelly and Clandinin's notions of personal practical 
knowledge as their core concept are a part of this research program. A similar grouping is made for Schön's work on reflective practice, Shulman's work on types of knowledge about teaching, and Cochran-Smith and Lytle's work on the teacher researcher.

The second definitional matter is the notion of knowledge type. A survey of the teacher knowledge literature turns up a host of knowledge names. Examples include strategic knowledge, propositional knowledge, relational knowledge, craft knowledge, local knowledge, case knowledge, situated knowledge, tacit knowledge, personal knowledge, and so forth. All these names do not necessarily pick out different types of knowledge. These knowledge names are, in some ways, like the names we give to people. Each of us has a given (formal) first name, usually a nickname, and often another name that is a family favorite; we may have still other names because of our membership in certain religious or social groups. These names all pick out the same person, though their context of use is different. While this aspect of naming is easily understood in connection with persons, it can be hard to follow with ideas or concepts. For this reason I restrict the term type to discrete epistemological categories, allowing the knowledge names to flower according to the preferences and inclinations of the researchers who coin, adopt, or adapt them. The notions of formal and practical knowledge mentioned above are instances of types of knowledge. More will be made of this point in the section that follows the overview; enough has been made of it here to carry us through the current section.

\section{A. What is known about effective teaching?}

This first question permits us to consider a key approach to the topic of teacher knowledge, that of the social and behavioral sciences (hereafter the expression "social sciences" includes the social and behavioral sciences). Though the question reads, What is known about effective teaching? it could as readily have been framed as, What is known about successful teachers? or What is known about what makes teachers good at what they do? The answer to these questions embraces all of the research that deals with relationships between or among variables, including nearly all of the process-product research, as well as a portion of the research pertaining to teacher thinking, cognitive processing, teacher expectancy, as well as a number of studies dealing with the topics of learning to teach and staff development.

This body of research does not explicitly mention teacher knowledge; it does not specifically identify itself as teacher knowledge research. Yet research programs that study relationships between variables entail a conception of knowledge about teachers and teaching that some believe to be critical for the advancement of the field. Researchers in this category do not see themselves as 
studying teacher knowledge so much as they perceive themselves producing knowledge about teaching. Using methods and designs found in the social sciences, they seek the determinants of good (successful, effective) teaching. Their work rests on a belief that if their methods and designs are in accord with accepted scientific theory and practice, their results may safely be accepted as knowledge about teachers and teaching.

This point of view is perhaps nowhere stated with more clarity and succinctness than in the work of N. L. Gage. In The Scientific Basis of the Art of Teaching, Gage (1978) sets forth his view of the relationship between science and teaching. The title of the book is carefully chosen, for Gage does not contend that teaching can or should be a science, but is rather an art based on a science. The science that Gage believes is the basis for teaching is psychology, particularly as practiced by university-trained research psychologists. In an update to The Scientific Basis, this one entitled Hard Gains in the Soft Sciences: The Case of Pedagogy, Gage (1985, p. 7) states that "a scientific basis consists of scientifically developed knowledge about the relationship between variables." Working within what might be called a standard or conventional conception of science, Gage argues that scientific knowledge is nomothetic (law-like), "it holds for the more or less general case under specified conditions with all, or all but a few, other variables held constant" (1985, p. 8). On how research gains its warrant, Gage $(1985$, p. 8) states that "nomothetic knowledge becomes more trustworthy as it is confirmed through replications, that is, repetitions of more or less similar investigations. Such confirmations add more to the persuasiveness of the evidence than does the statistical significance, no matter how strong, of a single result."

In a volume honoring Gage's contributions to research on teaching, David Berliner contended that "we are on the threshold of creating a scientific basis for the art of teaching that will be acceptable to the general public as truly specialized knowledge" (Berliner, 1987, p. 6, emphasis in original). Berliner goes on to argue that educational science has made practical contributions to education, among them "success rate, structuring, academic feedback, monitoring, motivating, expectancy, and wait time" (p. 18). In another effort to codify the knowledge accumulated through scientific studies for use by persons preparing to teach, the American Association of Colleges for Teacher Education commissioned a volume entitled, Knowledge Base for the Beginning Teacher (Reynolds, 1989). In his preface to the book, William Gardner wrote, "this book seeks to demonstrate that teaching does have a distinctive knowledge base .... This knowledge base has been generated in research ..." (Gardner, 1989, p. ix).

The AACTE Knowledge Base Project was an effort to draw together what was known at the time about effective or successful teaching, for use by teachers 
and teacher educators. Two other projects were also completed in the late 1980 's, both of them with a distinctive emphasis on the scientific understanding of teaching. The first of these was The International Encyclopedia of Teaching and Teacher Education (Dunkin, 1987), where many of the best known researchers on teaching summarized their work to date. In explaining the nature of this work, Michael Dunkin (1987, p. xiv) states:

"Substantive knowledge" as used here refers to information about teaching and teacher education obtained as a result of attempts to test hypotheses and answer questions about these two processes, their relationships with each other, and with other phenomena. Knowledge about teaching methods and other classroom occurrences is at the core of this Encyclopedia.

The other initiative was the third edition of the Handbook of Research on Teaching (Wittrock, 1986), a volume that many regard as the definitive compilation of what the American educational research community knows about teaching.

The science-oriented approach characteristic of these publications rests on a particular conception of knowledge. This conception is a modification of what is known as the standard, or justified true believe account of human knowledge. It is referred to here as Formal knowledge, and abbreviated TK/F. This knowledge is gained from studies of teaching that employ conventional scientific methods, quantitative and qualitative, where said methods and accompanying designs are intended to yield a commonly accepted degree of significance, validity, generalizability, and intersubjectivity. This formal conception of knowledge is different from the type of knowledge that characterizes research programs designed to answer the next question.

\section{B. What do teachers know?}

This question arises in the case of those researchers who want to know what teachers already know, in contrast to producing knowledge for teachers to use. A critical presupposition of research in this category is that teachers know a great deal as a result of their training and experience. A major contributor to this category of research, Clandinin (1986, pp. 8-9), contends that "teachers are commonly acknowledged as having had experiences but they are credited with little knowledge gained from that experience. The omission is due in part to the fact that we have not had ways of thinking about this practical knowledge and in part because we fail to recognize more practically oriented knowledge."

For purposes of this review, it is useful to divide into two strands the research that seeks to answer the question, What do teachers know? The first strand encompasses the work of Freema Elbaz and Connelly and Clandinin (and 
those research studies that spring from their work). The second strand is based on the reflective practice notions of Donald Schön, and is most evident in the work of Hugh Munby, Tom Russell, and a number of other Canadian and U. S. researchers (it is of more than passing interest that a significant portion of the research on teachers' practical or reflective knowledge is done in Canada). Both strands seek a better understanding of the knowledge teachers bring to their work and the understandings they have of it, although each strand rests on a different theoretical and methodological foundation. We will begin with the strand represented by Elbaz and Connelly and Clandinin.

Elbaz $(1991,1983)$ was one of the earliest contributors to this form of teacher research. Elbaz studied a high school teacher she called "Sarah" over a two year period, in order to gain a sense of what Elbaz calls her "practical knowledge." "This knowledge," writes Elbaz (1983, p. 5), "encompasses first hand experience of student's learning styles, interests, needs, strengths and difficulties, and a repertoire of instructional techniques and classroom management skills." Elbaz contended that the teacher's practical knowledge ranged over five areas, knowledge of self, milieu, subject matter, curriculum development, and instruction. Moreover such practical knowledge is represented in practice in three ways: First as rules of practice, which are "brief, clearly formulated statements of what to do or how to do it in a particular situation" (1983, p. 132); second, as practical principles, "more inclusive and less explicit formulations in which the teacher's purposes ... are more clearly evident" (p. 133); and third, as images, which in the case of Sarah are defined as "a brief, descriptive, and sometimes metaphoric statement which seems to capture some essential aspect of Sarah's perception of herself, her teaching, her situation in the classroom or her subject matter, and which serves to organize her knowledge in the relevant areas" ( $p$. 137).

As one reads Elbaz's study of Sarah, it becomes clear that her interest is in what Sarah knows or believes about her work, and how Sarah's understanding of her work might itself be understood. This approach is not that of a conventional scientific research program, where the focus would be on whether Sarah is instructionally effective, or on how she thinks given this or that theoretical orientation, or whether her actions are predicted by some theory. Instead, Elbaz seeks to grasp Sarah's knowledge of her working world, without imposing theory or established methods on the form of inquiry and without structuring Sarah's responses within an existing tradition of academic research. In undertaking this work, Elbaz finds that what Sarah knows is not theory, or empirical propositions, but how to carry out instructional tasks, resolve conflicts, adjudicate competing considerations, and connect aspirations to plans and then to instructional performance. Elbaz contends that these understandings make up Sarah's "practical knowledge." 
The notion of practical knowledge also figures prominently in the work of $F$. Michael Connelly and D. Jean Clandinin (Clandinin \& Connelly, 1987, 1991; Connelly \& Clandinin, 1985. 1988, 1990). They refer to the critical element in their work as "personal practical knowledge." Clandinin (1992. p. 125) describes this form of knowledge as follows:

We see personal practical knowledge as in the person's past experience, in the person's present mind and body and in the person's future plans and actions. It is knowledge that reflects the individual's prior knowledge and acknowledges the contextual nature of that teacher's knowledge. It is a kind of knowledge carved out of, and shaped by, situations; knowledge that is constructed and reconstructed as we live out our stories and retell and relive them through processes of reflection.

Those whose predilections are for more formal, more conventionally science-oriented, perspectives on the nature of knowledge will experience some consternation on reading this definition. It can be a challenge to follow Connelly and Clandinin as they work through their complex and elaborate conception of teacher knowledge. My own understanding of their work is helped by gaining a sense of their motivation, which will detain us only a moment. In her first booklength study of teacher knowledge, Clandinin (1986) describes her dissatisfaction as an elementary school counselor, in part because of the way theory and research were being imposed on teachers, and because the teachers with whom she worked had a number of negative experiences with school counselors. "In my work with teachers, I experienced a personal dissatisfaction with the way teachers are viewed. The prevailing view and organization of the educational enterprise give little credit to their knowledge" (Clandinin, 1986, p. 8). Over time, Clandinin came to reject the imposition of academic theory and research on teachers, preferring instead to try to understand how they think about their own work and what knowledge they use as a basis for their actions.

Recently Connelly and Clandinin $(1990$, p. 12) stated that "what is at stake is less a matter of working theories and ideologies and more a question of the place of research in the improvement of practice and of how researchers and practitioners may productively relate to one another." In taking teachers seriously as holders of practical knowledge, it becomes necessary for Connelly and Clandinin to find ways of learning what teachers know without employing methods that distort, destroy or reconstruct this knowledge. What they discovered in undertaking this form of inquiry is similar to Donald Polkinghorne's insight when he asked whether clinical practitioners had a better understanding of human psychopathology than researcher-theorists did: "Practitioners work with narrative knowledge. They are concerned with people's stories: they work with case histories and use narrative explanations to understand why the people they 
work with behave the way they do" (Polkinghorne, 1988, p. x). Connelly and Clandinin adopted the techniques of narrative and story (and the related concept of images) as ways of avoiding the excessive imposition of external theories and constructs on the personal practical knowledge of teachers. They argue that inquiries such as theirs must be "soft" or "gentle," else the storytelling urge will be stifled by the absence of trust between teachers and those who seek to understand what they know.

Using the notion of images, Clandinin probed the perspectives of the teachers with whom she worked. Clandinin views images as "the coalescence of a person's personal private and professional experience" (1986, p. 166). An image is "a way of organizing and reorganizing past experience;" it "embodies a person's experience; finds expression in practice; and is the perspective from which new experience is taken" $(1986$, p. 166). Images are conceptions that teachers have of their work that account for what they do. For example, one image is of the school as a second home for students, leading the teacher to think that she is a kind of custodial parent to her students, in charge of a classroom that is a home-like environment.

The notions of story, image, narrative, narrative unity and embodied knowledge are all central to the Connelly and Clandinin research program. Though they have taken some pains to explain these concepts (see, for example, Connelly and Clandinin, 1985, 1988, \& 1990), they remain puzzling concepts for many persons outside this research program. The notion of embodied knowledge, for example, is taken from the work of Mark Johnson, a philosopher who has argued that "human beings have bodies that are the locus of their complex interactions with their environment" (M. Johnson, 1989, p. 366; see also, M. Johnson, 1987). Johnson's contention that there are significant connections between the "structures of our bodily experience and what we regard as our 'higher' cognitive capacities" (M. Johnson, 1989, p. 366), while epistemologically provocative, is quite distant from the mainstream of contemporary scholarship in epistemology. The notion of "narrative unity," so strongly emphasized in the work that Connelly and Clandinin do with teachers, is based on the work of the ethical theorist, Alisdair Maclntyre (1984). While Connelly and Clandinin argue that the notion of narrative unity is central to their program, it remains a difficult concept to unpack with precision, especially in the context of classroom teaching.

These sentiments concerning the difficulties that can arise when using narrative and story as the basis of studying teacher knowledge are echoed in Carter's (1993) and John Willinsky's (1989) constructive critiques of the concepts and methods employed in this research program, as well as in related programs that employ techniques of story and narrative. It is possible, I believe, for a research program to be so heavily enmeshed in theory and conceptualization that it risks being blurred by it own abstractions. Connelly and Clandinin face that risk 
with their current initiative. On the other hand, this program offers both conception and method that tap what appears to be an important and frequently ignored type of human knowledge.

This second type of knowledge is here designated TK/P, or Teacher Knowledge/Practical. Teacher Knowledge/Practical is that knowledge or understanding developed from participating in and reflecting on action and experience. It is bounded by the situation or context in which it arises, and it may or may not be capable of immediate expression in speech or writing. TK/P is generally related to how to do things, or the right place and time to do them, or about how to see and interpret events related to one's actions. With this definition in place, we turn to the second strand of responses to the question, What do teachers know?

As Donald Schön examines practical knowledge, it is different from the conception put forth by Connelly and Clandinin. Schön grounds his work in the pragmatism of Dewey, and in his own studies of architects, psychotherapists and engineers. This work, set forth most explicitly in The Reflective Practitioner (Schön, 1983; see also Schön, 1987, 1991), rests on a profound dissatisfaction with what Schön calls Technical Rationality, as well as a search for a better way of understanding how professionals work in action. Technical Rationality is, in a nutshell, the application of conventional social science to the problems and tasks of everyday professional practice. It does not work, contends Schön, because it rests on a fundamental misconception of what professionals do. Their knowledge is not the knowledge of science, which occupies "the high, hard ground," populated with research-based theory, but rather is the knowledge of practice, found in the "swampy lowland where situations are confusing "messes" incapable of technical solutions" (Schön, 1983, p. 42).

For Schön, our knowing is in our action. Explicating this notion, Schön refers to such concepts as knowing-in-action, reflecting-in-action, reflecting-inpractice, and framing and reframing. These concepts are the heart of what Schön calls "the epistemology of practice." This notion is intended to set off the concept of theoretical, formal knowledge from that of practical knowledge. Schön's view is that not only are the sources of these two kinds of knowledge different, they are epistemologically different types of knowledge. Though I have been critical of the concept of an epistemology of practice (Fenstermacher, 1988), it now seems to me to be quite consistent with the larger notion of practical knowledge. Thus if one accepts practical knowledge as a legitimate epistemological type, a matter to be explored in the next section, the notion of an "epistemology of practice" is not nearly so troubling as it is if one confines oneself to formal knowledge as the sole, legitimate epistemological type. 
A number of excellent research studies are grounded in concepts propounded by Schön. Many of these can be found in The Reflective Turn, edited by Schön (1991); Teachers and Teaching: From Classroom to Reflection, edited by Tom Russell and Hugh Munby (1992); and Encouraging Reflective Practice in Education edited by Renee Clift, Robert Houston and Marleen Pugach (1990). Russell and Munby (1992, p. 2) state that "Schön's (1983) distinction between technical rationality and the knowledge of practice has drawn our attention to the significance of the knowledge that teachers acquire from their own experience." In contrast to Clandinin and Connelly, Russell and Munby do not argue that the narratives of teachers are prima facie examples of teacher knowledge. Moreover, they and other researchers committed to Schön's conception of reflective practice (see, for example, Erickson and MacKinnon, 1991, and Grimmett and Chehan, 1990) show a greater interest in how knowledge arises in the context of action as well as for the consequences of this knowledge for practice than in the description of this knowledge through narrative or story (hence the greater use of video tape to record the actions of teachers). Many of the researchers in this second strand have come to their conceptions of teacher knowledge through attempts to understand and improve the initial preparation of teachers.

In reading the research studies from both strands, one quickly gains a sense of different assumptions, different methods, and different outcomes. For example, in the Elbaz/Connelly/Clandinin strand, teacher knowledge appears to be inferred from narratives and stories (perhaps they would prefer to say that narrative and story revea/ the knowledge that teachers possess), while in the Schön/Munby/Russell strand, teacher knowledge is inferred from action that arises in the course of experience as a teacher. Another difference one senses in reading these studies is that Elbaz, Connelly and Clandinin seem prepared to accept teacher statements, stories and images as knowledge, while Munby and Russell (and like-minded colleagues such as Erickson, Grimmett and MacKinnon) are more cautious about according the status of knowledge to what teachers say or do.

Researchers in the Schön strand argue, as do Connelly and Clandinin, that teachers produce and possess their own knowledge, but Schön strand researchers consider it far more of a task to tease out precisely what knowledge is involved in action, and how this knowledge is altered in subsequent action. Researchers in the Connelly and Clandinin strand, on the other hand, appear to grant the teacher's insights the status of knowledge simply as a result of the teacher's having given expression to his or her conceptions of what took place in the classroom (this last comment may be inaccurate, for it is not clear to me whether the insights and understandings teachers express in narratives are accorded the status of knowledge merely because they are teacher- 
articulated insights and understandings, or whether they must first meet some categorical standard before being accorded the status of knowledge--this confusion may be stated in the form of a question, What is it that the teacher (knower) knows, and how is it known that the teacher knows it?).

Despite the differences between the two strands in approach and method, both strands seek a conception of knowledge arising out of action or experience, that is itself grounded in this same action or experience. Both strands show little patience for conventional social science methods, and for the epistemological conceptions that inhere to such methods. While their supporting theory and research methods differ, it is my sense that they are in pursuit of the same epistemological type (Jana Noel, 1993, makes a similar point with respect to the concept of intentionality that spans both these research strands). The Russell and Munby (1992) anthology, for example, includes chapters from both strands of practical knowledge. However there is little talk across the strands in the book, either in service to finding common interests or themes, or explication of important differences between the two. Given that both strands seek the explication of the same epistemological type, and that each uses novel and provocative methods for eliciting and understanding teacher knowledge, the explication of the concept of practical knowledge has much to gain from more dialogue between these two strands. Further dialogue is also likely to benefit a third approach to teacher knowledge, one that appears to employ both formal and practical versions of knowledge.

\section{What knowledge is essential for teaching?}

The research program that answers this question was launched by Lee Shulman in his wide ranging efforts to understand the nature of knowledge undergirding the enterprise of teaching (see, for example, Shulman, 1984, 1986a $\& b, 1987 a$ \& $b, 1989,1992)$. The groundwork for this program is laid in two important articles, one in the Harvard Educational Review (Shulman, 1987a) where Shulman set forth an argument for "the content, character, and sources for a knowledge base of teaching" (p. 4). The other is his 1985 presidential address to the American Educational Research Association, where he advanced the notion of pedagogical content knowledge (Shulman, 1986b). In the former piece, Shulman sets out the broad categories of knowledge required for teaching, while in the latter, he focuses upon a few of the categories dealing with content and pedagogical knowledge, contending that these are not nearly so well understood as the other categories of knowledge.

The research program that has emerged from these conceptions of teacher knowledge addresses questions of how students learn to teach subjects that they 
already know or are in the process of acquiring (Grossman, 1990; Grossman, Wilson \& Shulman, 1989; Wilson, Shulman \& Richert, 1987). Much of this work is about what Shulman calls "pedagogical content knowledge." Barbara Nelson (1992) opened her review of a book by one of Shulman's students with this comment: "In his 1985 presidential address, Lee Shulman tossed off the phrase "pedagogical content knowledge" and sparked a small cottage industry devoted to the scholarly elaboration of the construct ..." (p. 32). While the notion of "tossed off" seems a bit ungenerous, given the amount of scholarly development that went into the concept, there is no doubt that the concept has spawned an extensive set of research studies. What is difficult to ascertain in this work is whether it is distinctly formal or practical in type, or a blend of the two.

What distinguishes this work from that of, say, Elbaz, is that it is more normatively oriented. That is, it is rooted in a conception of what teachers should know and be able to do, with a concern for what categories and types of knowledge are required to achieve this state of competence (in the larger, more robust sense of the term). Elbaz, on the other hand, assumes a more descriptive stance, one that she hopes will reveal what teachers know and understand as a result of training, experience and reflection, not what a teacher should know in order to be successful or effective. (Note, however, that Elbaz's work has its normative dimensions; these are evident in her conception of how teachers ought to be viewed by those outside the occupation.)

Pamela Grossman (in press) alludes to this difference between the two research programs when she states that "studies of personal practical knowledge are not intended to inform as much as to illuminate classroom practice from teachers' perspectives" (p. 14). While Grossman does not so state, the suggestion is that the research program in which she and Shulman are engaged is tilted more towards informing than illuminating classroom practice. I do not wish to extract more meaning from this sentence than it was intended to impart, yet it nudges one further along a thought line that is suggested in reading Shulman's work on teacher knowledge: Formal knowledge has a larger role here than does practical knowledge, and perhaps even takes precedence over the practical.

It should not be inferred from this comment that Shulman is arguing for the precedence of experimental or correlational research results when compiling the knowledge base for teaching. He argues, for example, that, "the results of research on effective teaching, while valuable, are not the sole source of evidence on which to base a definition of the knowledge base of teaching" (Shulman, $1987 a$, p. 7). However, to say that the primary knowledge type in the Shulman research program is formal is not to restrict the range of this work to boundaries set for experimental or correlational studies. One can range well beyond these boundaries and still participate in the formalist conception. Shulman appears to do this quite successfully. 
There are, however, aspects of the Shulman program that suggest a strong interest in practical knowledge. In his presidential address, he distinguishes three forms of knowledge, propositional, case, and strategic knowledge. Case knowledge "is knowledge of specific, well-documented, and richly described events" (Shulman, 1986b, p. 11). Case knowledge is distinguished from case methods, which are "a particular strategy of pedagogical transformation--a strategy for transforming more propositional forms of knowledge into narratives that motivate and educate" (Shulman, 1992, p. 17). This reasoning suggests that cases and case methods are ways of transforming propositional knowledge into practical knowledge. Indeed, Shulman (1992, p. 21) argues that "from an epistemological perspective, cases may be more congruent with the forms of practical knowledge that undergird the varieties of practice, in teaching and other fields." There is, as you may have noticed, some confusion here. In the 1985 presidential address, Shulman argued that propositional and case knowledge are different, and that the three types of propositional knowledge are empirical and philosophical inquiry, practical experience, and moral reasoning. In the 1992 article on cases, he argues that case methods are a way to transform propositional knowledge into case knowledge, the latter being a type of practical knowledge.

Is this confusion the result of developing different perspectives in the seven years between ' 85 and '92? The span of time surely accounts for some of the change, for Shulman, like any active scholar, continues to refine concepts developed in earlier work. Yet development over time is not the sole explanation. Rather, what Shulman has been calling a type of knowledge seems more like a description of the way a practitioner holds the knowledge he or she has; she holds it propositionally, or as a story or narrative (case). Unfortunately this construction, while appealing as a way of making sense of propositional and case knowledge, will not work for strategic knowledge. Strategic knowledge, Shulman contends, is what we have when principles of practice conflict and we must act to resolve the conflict. This type of knowledge constitutes professional judgment, "the hallmark of any learned profession" (Shulman, 1986b, p. 13). Strategic knowledge appears to be the skilled adjudication of conflicts between the rules or principles (developed out of propositional knowledge) and the specific instances encountered in practice (cases or case knowledge).

Interestingly, strategic knowledge has the closest affinity to the notion of practical knowledge as exemplified by the TK/P category. In his description of it, Shulman does not say that strategic knowledge is a way of holding knowledge, while propositional and case knowledge do seem to be a way of holding knowledge. Both these latter categories, propositional and case, appear to be a blend of formal and practical types of knowledge, with a heavy dose of the formal, while strategic knowledge appears to fall well within the boundaries of practical knowledge. 
This confusion may be as much the result of my categories for analysis as it is of Shulman's conceptions of knowledge for teaching. Regardless of source, I believe the analysis does show that this program does not fall neatly under the first two questions, and cannot be grouped with any confidence as either TK/F or TK/P. Though Shulman and his colleagues clearly focus on the topic of teacher knowledge, in ways that have deepened our understanding of the interconnections between content knowledge and pedagogical knowledge, their epistemological framing is difficult to isolate and analyze. The discourses of the psychologist and the philosopher seem to merge in sometimes extraordinary and sometimes mysterious ways in this program, a point about which more will made when we look at conceptions of science later in this review.

\section{Who produces our knowledge about teachers and teaching?}

This question is prompted by the recent work of Marilyn Cochran-Smith and Susan Lytle (Cochran-Smith \& Lytle, 1990, 1993). Their research program establishes teachers as researchers, in contrast to university professors who do research on or about teachers. Based in part on earlier conceptions of action research, as well as on Schön's notions of knowledge-in-action and reflective practice, this program regards teachers as especially well positioned to conduct studies of teaching, learning and schooling. They call their program "teacher research," and define it as "systematic, intentional inquiry by teachers" (CochranSmith \& Lytle, 1993, p. 5). This inquiry is typically undertaken in the form of journals, essays, oral discussion and analysis, and more structured studies of classroom activities. They devote nearly two-thirds of their latest book (CochranSmith \& Lytle, 1993), to illuminating examples of these forms of teacher research.

The teacher research program is a part of this review because of a series of contentions it makes about teacher knowledge. In considering the notion of a knowledge base for teaching, Cochran-Smith \& Lytle (1993. p. 88) argue that "the question here is not whether we need a knowledge base for teaching but rather what kind of knowledge base is needed, who constructs it, and what roles teachers play in its formulation." Referring to their orientation as a "movement," they go on to contend that teachers must be more than consumers of universitybased research:

In contrast to the technical model of professionalization wherein the teacher is an increasingly sophisticated consumer of other people's knowledge, the teacher-researcher movement is based on the notion that a professional plays a participatory role in the creation and use of knowledge in the field. This relationship involves ways of knowing about teaching in which the teacher develops theories to "interpret, understand, and eventually transform the social life of schools" (Smyth, 1987, p. 12). (CochranSmith \& Lytle, 1993, p. 88, emphasis added) 
The writings of Cochran-Smith and Lytle leave little doubt that teachers should be among the producers (they often use the term generators) of knowledge. Though they do not explicitly suggest that university researchers of teaching ought to pack their bags, their enthusiasm for teacher researchers, combined with their frustration with the domination of teaching research by institutions of higher education, certainly suggests that university-based researchers should rethink the nature of their work. The question of who produces knowledge of teaching evokes memories of some of the criticism I, as a university-level scholar, received on venturing into this arena. A momentary autobiographical reference offers what I trust will be some further illumination on the important distinction between who makes and who consumes teacher knowledge.

In preparing an article for the third edition of the Handbook for Research on Teaching (Fenstermacher, 1986), I tried to work out the relationship between social science research on teaching and the uses that teachers might make of this research. In doing so, I found it helpful to draw a distinction between knowledge production and knowledge use, contending thereafter that scientists produced knowledge and teachers used it. For this construction, I was roundly, and I now believe rightly, criticized by some of my Canadian colleagues who offered Schön's work as a counter to mine (see Fenstermacher, 1987; Kilbourn, 1987; Munby, 1987; and Russell, 1987). Teachers, they retorted, are more than simply passive consumers of knowledge; they are producers of it as well, and users of their own knowledge as well as that produced by others. Cochran-Smith and Lytle make similar contentions, building up the theoretical rationale for these contentions as well as exploring methods and procedures for teachers becoming engaged in their own research.

At the time I made the producer/user distinction, I was thinking of teachers as engaged in a quite different form of inquiry from that employed by academic researchers. That inquiry, I argued, was practical, in contrast to the formal inquiry of university researchers. I will, with but a few exceptions, continue to defend this position. However, what I did not contend then, but would do now, is that practical inquiry yields a form of knowing just as formal inquiry does. Additionally, I believe the forms of inquiry employed by university-level researchers and elementary and secondary school teachers are typically different, though they need not be differentiated by occupational role (Richardson, in press/a, provides an extended discussion of formal and practical inquiry, indicating how both may be done by either researcher or practitioner). That is, a teacher may engage in formal or practical inquiry, depending on the problem studied, the methods employed, and the intended scope of the results. A researcher may as well engage in either form of inquiry. 
This last paragraph introduces a new twist in the analysis. Up to this point, formal and practical knowledge have been the focal concepts, whereas formal and practical inquiry now appear to be important conceptions. In anticipation of considerations yet to come, I will note here a quite tight connection between the form of inquiry one employs and the type of knowledge one produces. This distinction is not sharply drawn in the work of Cochran-Smith and Lytle, which leaves open the question of whether they are opting for a practical or formal conception of knowledge. Perhaps they would opt for a blend of the two, as, on occasion, seems to be Shulman's preference. This option, however, may create considerable difficulty for both research programs, as will be illustrated when we turn to consider conceptions of science undergirding teacher knowledge research. The question that will concern us there is whether the two forms of inquiry are so rooted in opposing epistemological foundations that they cannot peacefully co-exist.

Let us complete the answer to the fourth question, who produces knowledge of teaching, with the observation that, like Shulman, Cochran-Smith and Lytle do not propose types of knowledge substantively different from those mentioned in answer to the first two questions. Instead, they propose to relocate, or at least co-locate the sources of our knowledge about teaching. The type of knowledge subject to relocation is not entirely clear; it may be formal, or practical, or both. When looking at this research program through the lens of TK/P, one notes the acknowledgement that Cochran-Smith and Lytle give to the work of Schön. This modest overture to TK/P may be due to several factors. It might be that the exploration of espistemological types is simply not so vital to CochranSmith and Lytle as the matter of where and how such types are produced. Another possibility is that Cochran-Smith and Lytle implicitly believe that the relocation will go better if the university is a willing partner in the enterprise, a more likely outcome if formal rather than practical knowledge is stressed in arguments for teacher research. A final possibility is that a fair portion of the TK/P research rests on an epistemological foundation that is still "under construction." As such, it may strike these two scholars as tactically unwise to emphasize the production of practical over formal knowledge.

Any of these possibilities would explain the relative inattention to TK/P in the Cochran-Smith and Lytle program, although none of them may accurately represent the thinking of Cochran-Smith and Lytle. For the moment, we simply cannot be sure whether one knowledge type is favored over another, or even whether Cochran-Smith and Lytle care to draw the knowledge type distinction. The upshot of all this is that this research program is rooted more in matters of who makes our knowledge about teaching, and where it is made, than in what types of knowledge result from the activity. 
With these remarks in answer to the fourth question, the overview of research programs may be brought to a close. Four questions were posed and answered, in ways that led to the identification of two major types of knowledge, formal and practical. Not all research programs discussed fall neatly into these two knowledge categories, as not all of them are efforts to specifically address epistemological issues. Several of the programs that are not especially sensitive to or concerned with epistemological issues engender ambiguity about what types of knowledge they are striving to study or produce. This ambiguity may be unproblematic, though we will soon see that it may also be quite the reverse. One cannot make much more progress in understanding the epistemological issues, or in examining the conceptions of science upon which these research programs are based, without considering epistemology itself.

\section{CONSIDERATIONS FROM EPISTEMOLOGY}

The preceding overview identified two primary conceptions of knowledge, formal and practical. In this part, these two conceptions will be examined in detail by connecting them to considerations from that branch of philosophy called epistemology. Many people regard this area of philosophy as preoccupied with questions of what we know and how we know it. True enough, though it also includes such topics as causation, empiricism, intuition, reasoning, sense data, and universals. One of the most succinct definitions of the field is offered by $D$. W. Hamlyn (1967, pp. 8-9): "Epistemology, or the theory of knowledge, is that branch of philosophy which is concerned with the nature and scope of knowledge, its presuppositions and basis, and the general reliability of the claims to knowledge."

Epistemologists differ on how many different types of knowledge there might be, though there is a clear fondness--as in most academics--for the view that there are three types. David Pears (1971) makes the common tripartite distinction among, (1) factual or propositional knowledge, (2) knowledge of how to do things, and (3) knowledge by acquaintance. Keith Lehrer (1990a) describes a similar division as he examines different senses of the expression "to know," ranging from (1) recognizing something as information, to (2) having some special form of competence, to (3) being acquainted with someone or something. Albert Jonsen and Stephen Toulmin (1988, pp. 58-59) credit Plato and Aristotle for three main types of knowledge: "theoretical comprehension of abstract arguments in the sciences, practical command of general craft techniques, and the prudential wisdom that is required to handle particular legal problems or medical cases." In addition to these more or less standard categories, there is the tacit knowledge described by Michael Polanyi $(1964,1966)$, which is often considered a subspecies of one or more of the three categories mentioned just above. 
There is also a growing body of literature that touches on differences between men and women with respect to knowing. Lorraine Code (1991), Carol Gilligan (1982), and Mary Field Belenky, Blythe McVicker Clinchy, Nancy Rule Goldberger, and Jill Mattuck Tarule (1986) are among the more widely cited of this literature. The persuasive arguments offered by these scholars require our consideration of how contentions about women's ways of knowing relate to contentions among epistemologists (nearly all of them male) that there are three types of knowledge. There is, I believe, a useful distinction to be drawn between types of knowledge and ways of knowing. The former concerns the nature of the knowledge we hold, while the latter pertains to how we come to achieve this knowledge. It is quite possible that where two people have different ways of knowing, they will come to know different things, that is, the knowledge held by one will be different from the knowledge held by the other. However, the epistemological type of that knowledge may not differ. A male and a female may hold their knowledge differently, or hold different knowledge, while the epistemological category into which this knowledge falls is unchanged from the categories mentioned at the beginning of this section.

This distinction does not permit us to now set aside the critical examination of male-dominated or male-oriented scholarship. The problem is that even though epistemological types of knowledge may be unaffected by differences in ways we come to know, the descriptions of the types themselves are the product of gender-specific philosophizing. While this problem is quite real, it is one I am unable to address here. It must suffice to note that the epistemological types mentioned above are a useful way to understand important differences in the kinds of knowledge we hold, and they possess utility for the analysis undertaken in this review. Still, it is well to keep in mind that continued feminist scholarship in philosophy may diminish the value of these types or devise more powerful and inclusive concepts for understanding the nature of our knowledge.

Of the several epistemological types mentioned above, our interest is in two of them. The first is propositional or informational knowledge; the second is knowing-how or competent performance. These two types serve as the basis for the distinction between TK/F and TK/P, although there is more involved in the TK/F and TK/P categories than is fully captured by the usual differences between propositional and skill knowledge (or, as it is sometimes phrased, "knowing that and knowing how"). Propositional knowledge has been the mainstay of AngloAmerican epistemology, from the time of Plato until the present. This type of knowledge is variously referred to as scientific knowledge, propositional knowledge, informational knowledge, and theoretical knowledge. Some of this terminology is derived from the distinction between the Greek terms 
epist ' $m$ ' and techn'. Since Aristotle, the term 'epist' $m$ " has referred to knowledge about the world that can be established to a very high level of confidence, while 'techn" has referred to knowing how to do something (a skill, craft or art).

It is epist ' $m$ ' that has received the major share of the epistemologist's attention, and thus has garnered the privileged position in any compendium of knowledge. Moreover, for many epistemologists, the paradigmatic instance of epist ' $m$ ' is scientific knowledge. The general regard for knowledge of this kind is evident in Charles Van Doren's A History of Knowledge. Van Doren (1991, p. 184) contends that "Of all the kinds of knowledge that the West has given to the world, the most valuable is a method of acquiring new knowledge ... called "scientific method." Van Doren's profuse praise of this type of knowledge offers considerable insight into its place in any hierarchy of knowledge:

There are other kinds of knowledge beside scientific knowledge, ... but none of them, at the present time and in the foreseeable future, has the power, prestige, and value that scientific knowledge has. Science has become the most distinctive of human activities, and the indispensable tool for the survival of the billions who now inhabit the planet. (1991, p. xxiv)

In contrast to epist ' $m$ ', techn' has received scant attention in the history of Western philosophy. In her now-classic study of intention, G. E. M. Anscombe $(1963, \S 32$, p. 57) asks, "Can it be that there is something that modern philosophy has blankly misunderstood: namely what ancient and medieval philosophers meant by practical knowledge? Certainly in modern philosophy we have an incorrigibly contemplative conception of knowledge" (emphasis in original). Since Anscombe raised this question, there has been a revival of interest in practical knowledge, though much of the discussion has taken place in the sub-area of epistemology known as philosophy of mind. Both types of knowledge, propositional and performance, require further analysis if we are to understand their connections to the teacher knowledge literature. We with propositional knowledge.

\section{A. The Character of Propositional Knowledge}

In the lingo of philosophers, letters of the alphabet are pressed into service as proxies for people, things and ideas, with upper case letters for people and lower case for concepts or statements. When the epistemological type is propositional, its analysis might proceed in this way: In order for a person, $S$, to be said to know something, let us call that something $p$, it is not sufficient that $p$ is true and that the person, $S$, believe $p$. It must also be the case that $S$ has grounds for $p$. This view of knowledge is often called the classical view, or the 
"standard analysis" of knowledge (Shope, 1983). It has been succinctly described by the philosopher, Edmund Gettier (1963), who is frequently credited with dealing it a near-knock-out punch. The standard analysis reads as follows:

\author{
$S$ knows that $p$, if and only if \\ (i) $p$ is true \\ (ii) $S$ believes that $p$, and \\ (iii) $S$ is justified in believing that $p$.
}

(Gettier (1963, p. 121)

The standard analysis establishes strict conditions for a knowledge claim. The claim must be true, it must be believed by the claimant, and the claimant must be justified in believing the claim. Thus where $p$ refers to the proposition, "The earth has a spherical shape," in order for some person $S$ to be said to know $p$, it must be the case that, (i) it is true that the earth has a spherical shape (this condition is established within the discipline that concerns itself with propositions of this type), (ii) $S$ believes that the earth has a spherical shape, and (iii) $S$ has justification for believing that the earth has a spherical shape.

The standard analysis has sometimes been called the "justified true belief" or JTB account of knowledge. Gettier's (1963) critique posed a series of counterexamples to the standard analysis that led to number of attempts to repair the weaknesses he exposed. Much of the ensuing concern has been with the meaning of true in the statement " $X$ is true," and with what constitutes a proper justification for $S$ s believing that $p$ (see, for example, Chisholm, 1989, Lehrer, 1990a \& b, Pappas \& Swain, 1978, Shope, 1983). It would be a serious misunderstanding of the consequences of Gettier's counterexamples to infer that there is no longer a satisfactory or commonly accepted conception of what it means to know something in the propositional or informational sense of the term. A large number of contemporary epistemologists are in agreement that we can have knowledge of the world, that there are specific conditions that must be met if our claims to knowledge are to succeed, and that some form of justification is required as one among these conditions. The issue of justification, in epistemology, is over the particulars of what constitutes a defensible justification, not over whether justification is required. It will always be the case, as near as can be foretold, that some form of justification will be required if we are to know, as Lehrer (1990b, p. 253) puts it, "that the information one receives is correct."

Gettier's critique and a host of related analyses have put an end to conceptions of formal knowledge as pristine, permanent, and absolute. Again, however, it would be an error to conclude that because our knowledge is fallible, it is therefore useless to worry about what it means, or that it is simply too confusing to take seriously any epistemological account of knowledge. Fallibilism, the view that we can be wrong about we claim to know, is a fairly well accepted 
doctrine among contemporary epistemologists; it is not regarded as devastating in its consequences for a well-wrought theory of knowledge. Nor can we ignore the demands of justification on the grounds that do not have the rock-solid, goldplated conceptions of truth that once graced theories in epistemology.

Consider Anthony Quinton's (1967, p. 346) reaction to the claim that if knowledge entails truth, we can never know anything:

This objection is misconceived. If I firmly believe that something is true on what I take to be sufficient grounds, I am right to say that I know it. It may be that the grounds are, in fact, insufficient and that what I claim to know is false. In that case my claim is mistaken, but it does not follow that I was wrong to make it in the sense that I had no justification for doing so.

Although he occupies a position in epistemology that departs in several respects from the position I have taken in this chapter, Roderick Chisholm provides a helpful way to think about issues of justification and truth. He sets forth what he calls "The 13 Steps" for considering the epistemic status of knowledge claims (Chisholm,1989, p. 16), as follows:

+6. Certain

+5 . Obvious

+4 . Evident

+3. Beyond Reasonable Doubt

+2 . Epistemically in the clear +1 . Probable

0 . Counterbalanced

-1. Probably False

-2. In the Clear to Disbelieve

-3. Reasonable to Disbelieve

-4. Evidently False

-5 . Obviously False

-6. Certainly False

These steps provide a good feel for how epistemologists look at what I am calling formal knowledge. Although for Chisholm a proposition cannot be known until it attains the fourth, positive step (Evident) or above, other epistemologists would entertain a proposition's having epistemic merit at the level of "Beyond Reasonable Doubt." At the fourth, or Evident, step, the proposition meets modified standards for what is known as justified true belief. For other epistemologists, a claim is sufficiently justified to count as knowledge if it is reasonably believed by the holder, the holder having sufficient evidence to establish the claim against its competitors. This notion is parallel to the idea of 
"objectively reasonable belief" described by Green (1971) in his analysis of knowledge and belief in education.

Some epistemologists doubt whether objectively reasonable belief counts as knowledge. Oliver Johnson (1980) argues for a distinction between reasonable belief and knowledge, concluding that we should "reserve the term 'knowledge' for beliefs whose truth we can justify" (p. 126), and use the expression "reasonable belief" in cases where we cannot justify the truth of the proposition but "for which we can offer reasons that we believe in some sense to be 'good'" (p. 126). This view is consistent with Chisholm's, in that what is just below the level of Evident is not knowledge, though it is based on sufficient reasons as to be beyond reasonable doubt. However, there is some debate on the matter of when (and how) a proposition flips from being "reasonable belief" (or, as Green would say, "objectively reasonable belief") to being properly identified as knowledge. Without becoming mired in this debate, it is sufficient for our purposes (and in accord with a fair body of epistemological thought) to hold that a proposition is known by its holder if the holder believes the proposition and has evidence to establish its reasonableness in relation to other, competing claims.

Objectively reasonable belief may not be a sufficiently strong standard to sustain the concept of knowledge as it is currently used in the social or natural sciences (though this point is also subject to debate), yet if this standard is met in teacher knowledge claims there are few who would quibble over half a notch or so on Chisholm's scale. An even "softer" version of standards for knowledge stipulates that what counts as knowledge in a given context is relative to what is already known in that context. If an assertion is about matters of which little is known, we may be entitled to say that we know $p$, with only modest justification. In other words, "It's the best we've got" at this time and so we are entitled to claim to know it. In areas where more is known, our obligation to address this evidence and consider it in relation to our own grounds for believing the proposition is correspondingly increased. No softening of the standards may, however, go lower than Chisholm's "epistemically in the clear," by which is meant that the holder can show that there are not better grounds for rejecting the proposition than for accepting it. Clearly this is a weak standard; any claim to know $x$ on this standard is highly suspect, and would have to be made in a context where there was little or no evidence available to guide consideration of the proposition.

In summary, the analysis of propositional knowledge offers some latitude for interpretation, but does not permit definitional anarchy. It its strict form, knowledge continues to be understood as a form of justified true belief, though without a sense of the absolute, permanent qualities that once attached to this notion. A more modest standard permits us to make knowledge claims on the basis of objectively reasonable belief. An even milder form permits us to gauge our knowledge claims in relation to the evidential character of the context in 
which the claim is made, thereby "allowing" one to claim to know something without meeting the standard criteria for objectively reasonable criteria. In my own case, I believe that objectively reasonable belief is an acceptable form of knowledge within the context of educational practice (though it may not satisfy the canons for educational research, at least not in the more conventional science conceptions of educational research). The even milder version, what might be called the contexted knowledge version, is feasible, but should be employed with great caution.

Given the view of propositional knowledge presented here, one can see how the following definition of knowledge, taken from a recent article in the Review of Educational Research, might bruise the sensitivities of an epistemologist:

For researchers in the field of cognition and literature, it goes nearly without saying that knowledge refers to an individual's personal stock of information, skills, experiences, beliefs, and memories. This knowledge is always idiosyncratic, reflecting the vagaries of a person's own history.... In the literature we are reviewing here, knowledge encompasses all that a person knows or believes to be true, whether or not it is verified as true in some sort of objective or external way. (Alexander, Schallert \& Hare, 1991, p. 317; emphasis in original).

The authors argue that "this use of the term knowledge contrasts with the use of the term in the field of epistemology, where knowledge often refers to justified true beliefs and is reserved for universal, or absolute, truths" (p. 317). As I hope is now clear, the concept of knowledge within contemporary epistemology has a far broader range than is presumed by these writers. However, the position they identify does raise a noteworthy distinction between the way the term knowledge might be used in, say, social science and its use in epistemology. More will be made of this distinction in a later section.

\section{B. The Character of Performance Knowledge}

What epistemologists have generally called "knowing how," skill knowledge, or competent performance, is here referred to as performance knowledge. It is typically considered to be quite distinct from propositional knowledge. Many of us, on hearing the notion of performance knowledge, think of the difference made famous by Gilbert Ryle (1949) between knowing that and knowing how. Of course the distinction predates Ryle by a few thousand years, though Ryle is generally credited with reintroducing the topic into Anglo-American philosophy. In its Greek form, it was, as already noted, discussed as techn'. 
As such it was knowing how to make something, a skill or capacity for the exercise of some craft. Building a house, playing the lute, or translating languages are good examples.

Mark Johnson, a philosopher on whose work Connelly and Clandinin base their notion of embodied knowledge, argues for a view of knowledge that "grows out of one's personal experience and is the very means of transformation of that experience" (M. Johnson, 1989, p. 364). Johnson then argues that seen in this way, "personal practical knowledge is a quite similar to the classical Greek conception of techn" (p. 364). Elaborating on the connection between techn" and personal practical knowledge, Johnson writes:

The association of personal, practical knowledge with techn' broadly defined is not meant to suggest that we are dealing only with a form of "know-how." On the contrary, following Dewey, I wish to reject the whole dichotomy between "knowing that" ... and "knowing how" .... No good has come from this alleged crucial epistemological distinction, which has served only to give us a picture of ourselves as cognitively fragmented, and which has reinforced the ill-conceived "theory/practice" dichotomy. (M. Johnson, 1989, p. 365)

My own sense is that only a philosopher, and then only a few of them, could feel "cognitively fragmented" by the distinction between knowing how and knowing that. Clearly our use of everyday language acknowledges a difference between the two, as most people deal differently with a claim like "I know that smoking is the leading cause of lung cancer" than they do with a claim like "I know how to smoke a pack of cigarettes all at once." To the former claim we say, "What evidence do you have to substantiate such a claim?" while to the latter, we say, "Oh, really! Show me." Indeed while Johnson appears to opt for collapsing the two forms into some new category, much of the philosophical discussion of the knowing- how/knowing-that distinction has been on whether knowing how is dependent on knowing that for its for its justification.

Because a considerable portion of the TK/P literature is concerned with the "know how" that teachers accumulate through experience and reflection, it is worth pursuing the distinction a bit further. Ryle (1949) provides the best known, if not the most explicit modern discussion (though Israel Scheffler, 1965, provides an extensive analysis of this and related concepts as they bear on the concept of education). Concerned with what he regarded as fundamental errors in the Cartesian view of the relationship of mind and body, Ryle set out to offer a correction to the dualist thesis (that mind and body are separate, but interrelated). This correction involved, among other things, arguing that knowing how could not be reduced to knowing that. In one of the conclusions he draws on this point, 
Ryle (1949, p. 30) states, "It is therefore possible for people intelligently to perform some sorts of operations when they are not yet able to consider any propositions enjoining how they should be performed." If it were in fact necessary, argues Ryle, to consider such propositions, it would create a most confounding difficulty: "If for any operation to be intelligently executed, a prior theoretical operation had first to be performed and performed intelligently, it would be a logical impossibility for anyone ever to break into the circle" (p. 30).

Ryle's compelling prose and evocative arguments have convinced many readers that knowing-how and knowing-that are distinct domains, independent of one another. On the other hand, there is some consideration in the philosophical literature that knowing how is, in an important sense, dependent on knowing that. For example, in A. J. Ayer's (1956) well-known work, The Problem of Knowledge, he states that under certain conditions "we can construe knowing how to do things as being, in its fashion, a matter of knowing facts" (pp. 13-14). More recently, Lehrer (1990a, p. 4) remarked that "it is often affirmed that to know something in the other senses of 'know' [i.e., competence and acquaintance] entails knowledge in the information sense of 'know'."

If there is indeed a tighter connection between knowing-how and knowingthat than presumed by Ryle, it becomes problematic for someone to opt for a knowing-how version of knowledge as a way of rejecting a knowing-that version, or of saying that knowing-how replaces knowing-that as the primary, quintessential or unique characterization of teacher knowledge. Consider the example of my claiming to know how to play bridge. In making this claim, I am also asserting that I know that hearts and spades take precedence over diamonds and clubs, I know that a one no trump bid overrides a one spade bid, I know that a Blackwood convention is called for when ..., and so forth. It may equally be true that the knowing-that/knowing-how connection also works in the other direction, such that we cannot know that without knowing how. For example, to know that all electrical outlets in my home supply 115 volt current, I have to know how to use a voltmeter (or know how to read the scale of a voltmeter operated by someone else I followed around the house). There is also the question of how much knowing-that we could have in the way of scientific information without the knowing-how of scientific methods. The point to be made here is that it seems one cannot opt for performance knowledge without also understanding that one has "acquired" propositional knowledge in the bargain, and vice versa.

One should not conclude from this positing of an interrelationship between knowing-how and knowing-that that I am arguing that they are really one in the same, or that one is reducible to the other. Quite the contrary, I am on the side of the Greeks on this matter, believing that while the two are distinct, they are interdependent. Departing from Ryle, however, I believe that the justification of 
performance knowledge is every bit as important to its epistemic status as it is in the case of propositional knowledge, and that such justification is not simply in the performance of the skill or the craft but also in establishing the reasonableness of the performance and the evidence connecting its purpose to its eventual outcome. With this stipulation in mind, it is time to address the connections between propositional and performance knowledge, on the one hand, and formal and practical knowledge, on the other.

\section{Distinguishing propositional knowledge from $T K / F$, and performance knowledge from TK/P}

It is tempting to contend that what epistemologists call propositional knowledge is the same as what I have identified as Teacher Knowledge: Formal, and that performance knowledge is the same as Teacher Knowledge: Practical. While there are clear affinities between the categories, it is an unwise move to conflate formal with propositional, and practical with performance. One obvious reason is the lack of precision in the concept of practical knowledge, as it is used across the several teaching research programs. Even though a significant share of this concept might be explained by the epistemological notion of performance knowledge, far more falls with the domain of TK/P than is accounted for in the philosopher's concept of performance knowledge.

Furthermore, as the notion of TK/F is developed here, there are strong connections between certain methods of inquiry (i.e., scientific research) and claims to formal knowledge. Thus as developed in this chapter, there are certain standards of significance, generalizability or validity (in the broadest sense of these terms) that must be met to properly claim that one is in possession for formal knowledge. These standards are introduced here in part because this chapter is about teaching research. Thus to properly claim that one is in possession of formal knowledge, one's knowledge claims must be justified in such a manner that they range beyond the immediate context, situation, or slice of time. In the epistemological literature, a straight propositional claim might be highly constrained by time and context, and still meet epistemological criteria for counting as knowledge. That is, a proposition may be quite specific or time bound, yet still pass epistemological muster as knowledge. In contrast, what I have called formal knowledge will not survive epistemological scrutiny as knowledge if it is restricted in its application to time, place, and situation.

Practical knowledge, on the other hand, is bounded by time, place or situation. To claim to know something practically is to claim to know something about an action, event or situation in this particular instance. Practical knowledge consists in some part of what epistemologists call performance knowledge, though it ranges well beyond this limited notion of performance or competence (to include, for example, what Jonsen and Toulmin (1988) call prudential wisdom, or what Shulman (1986b) calls strategic knowledge). Thus 
even though the notion of TK/P is in large measure rooted in the epistemological concept of performance knowledge, it is often discussed in the literature as a much broader, more inclusive concept.

With these connections in mind, the critical epistemological point can be made: Both TK/F and TK/P are subject to evidentiary scrutiny if there are to count as knowledge in any useful sense of the term. That is, to claim that we know something about teachers or teaching, or that teachers know something about teaching, it must be the case that we can be in error, that we understand what would count as showing that we are in error, and that we have a basis for establishing that we have not made an error. That we claim to have practical knowledge does not relieve us of the obligation to show how it is objectively reasonable to believe what we are contending. Justification or warrant are as vital to TK/P claims as they are to TK/F claims, though they are different undertakings depending on the domain in which one stakes one's claim. What distinguishes this effort in the practical, as opposed to the formal domain, is that we do not require the methods or other paraphernalia of science to do this.

Part IV of this review, covering the scientific study of teaching, provides further discussion of the differences between formal and practical knowledge in research on teaching. Deferring this discussion until later in this chapter permits us to move on to another critical epistemological feature, the relationship between knowledge and belief.

\section{Knowledge and belief}

It is an eye-opening experience for a student of epistemology to note how knowledge and belief are grouped together in so many accounts of teacher knowledge. As I hope is now evident, a claim to know something is epistemologically different from simply having a belief in something. Consider, as an example, the proposition, "Harry's car is parked in garage A, lower level." If you were to probe the epistemic status of this claim, you might get one of these three different responses:

(1) I saw his car parked there this morning when I parked my car, and his secretary says she still has the car keys he left with her when he arrived.

(2) Harry always parks his car on the lower level of A.

(3) Guys like Harry prefer the lower level of A.

Response (1) has a higher epistemic status because it is characterized by the evidence of actually seeing Harry's car on level A and having the testimony of a reliable person that Harry could not have moved his car since it was observed in the garage. Claims (2) and (3) exhibit diminishing epistemic status due to the falloff in evidentiary support and the increasing difficulty of setting out a convincing 
justification. However, in all three instances there is no prima facie difficulty in saying that the person believes that Harry's car is parked in the lower level of $A$, whereas there is an increasingly serious problem, as one moves from (1) to (2) to (3), with saying that the person knows that Harry's car is parked on the lower level of $A$.

This distinction, so commonly drawn in epistemology, is not so commonly used in research on teacher knowledge. Sometimes this state of affairs is unproblematic, as when the term 'knowledge' is being used as an inclusive group name. This appears to be the case for the use employed by Patricia Alexander, Diane Schallert, and Victoria Hare (1991), quoted a few pages earlier, when stating that knowledge "refers to an individual's personal stock of information, skills, experiences, beliefs, and memories" (p. 317). In this grouping or categorizing sense of the term, to call all these cognitive events or mental states "knowledge" is not to make any claims about their epistemic status. The grouping or categorizing sense of the term is consistent with such dictionary definitions of knowledge as "familiarity, awareness or understanding gained through experience or study; the sum or range of what has been perceived, discovered, or learned" (The American Heritage Dictionary, 3rd ed). This grouping sense may also be the basis for Dona Kagan's (1990) clustering of knowledge and belief, although this case is less clear than the Alexander, Shallert and Hare example. Kagan states that she often uses "belief and knowledge interchangeably .... I do so in light of mounting evidence that much of what a teacher knows of his or her craft appears to be defined in highly subjective terms ..." (1990, p. 421).

This is a puzzling contention, for it seems to acknowledge that knowledge and belief might be distinguished by notions of objectivity and subjectivity, respectively, yet the decision here appears to be treat them as having the same epistemic quality because of the apparent subjectivity of what teachers "know." I believe that Kagan would be on firmer ground were she to contend that the terms knowledge and belief are sometimes used in some research programs as if they were identical in meaning and epistemic status, and thus she will use them interchangeably. However, the moment she bases the decision to use the terms interchangeably on the notion of subjectivity, she raises the general issue of epistemic import. It is precisely in this event that the distinction between knowledge and belief must be drawn.

Given what appears to be a growing tendency in the educational research literature to discuss knowledge and belief as if the terms were synonymous, there is much to be gained from making a distinction between using knowledge as a grouping or classifying term, on the one hand, and using it to imply or entail the relative epistemological merit of one's claims, on the other. When used as a grouping term, we may with impunity, include all sorts of phenomena under the 
heading "knowledge," including insights, imaginings, musings, awareness, understanding, recollections, predictions, anticipations, and a host of other activities of mental life. In defining knowledge in this way, we would be making no claims about the epistemic status of these mental states or events, or the written or spoken outcomes of these mental activities. In making this distinction, we could preserve the epistemological distinction between knowledge and belief, while not denying ourselves a convenient way of categorizing mental events and outcomes that are important to research programs in the field of teacher knowledge.

Though I believe this distinction is a worthwhile analytical device, it does constrain what is included in the category of things called knowledge. Though I believe there are good reasons for such constraints, it is important to note that some philosophers disagree. Among them is Paul Feyerabend, who, while considered something of a radical among his philosophical colleagues, is an adept and powerful spokesperson for his views. After noting a host of diverse sources and kinds of knowledge, Feyerabend (1987, p. 115) states:

The social groups who prepared what is now known as Western rationalism and who laid the intellectual foundations for Western science refused to take this abundance [of forms of knowledge] at face value. They denied that the world was as rich and knowledge as complex as the crafts and the commonsense of their time seemed to imply.

Though I am in sympathy with the general approach Feyerabend takes to the nature of knowledge (as I hope later sections of this chapter will make clear), I continue to believe that a claim to know is a special type of claim, different from a claim to believe, requiring justification in ways that beliefs do not. Feyerabend may even agree, though his tolerance for what is knowledge is so broad that it is difficult to hold his views and sustain the distinction drawn here.

The main point of this discussion of knowledge and belief is that there are important differences between the two if one intends to make claims about epistemic import. When, for example, a researcher argues that teachers produce knowledge in the course of acting on experience, one could be saying merely that teachers generate ideas, conceptions, images, or perspectives when performing as teachers (the grouping sense of knowledge), or that teachers are justified in performing as they do for reasons or evidence they are able to provide (the epistemic status sense of knowledge). Aspects of this distinction, as well as the larger issue of the differences between knowledge and belief, are also apparent when examining variations on the teacher knowledge theme, such as local and tacit knowledge. 


\section{E. Local, Craft, Situated and Tacit Knowledge}

There are a number of permutations on the formal/practical distinction that frequently appear in the teacher knowledge literature. Understanding where and how these fit into epistemological discourse is essential if one is to have a grasp of how these variant forms of knowledge bear on the analysis of this chapter. Because my purpose is only to suggest how these variant forms fit into the framework of this chapter, my accounts will be too brief to acknowledge both the obvious merits and possible shortcomings of this work.

Though the concept of local knowledge is discussed by Geertz (1983) and a number of other anthropologists, the application of this concept to teaching is well illustrated in a multi-year study of reading achievement among Spanishspeaking children by Goldenberg and Gallimore (1991). In this work a distinction is drawn between local knowledge and research knowledge. Local knowledge is defined in a way that appears to place it within the category of TK/P. For Goldenberg and Gallimore, local knowledge is direct experience with how things work. It is, they argue, prior to research knowledge, which "cannot have a direct bearing on practice because it is oblivious of compelling local issues that frame the thinking and drive the behavior of practitioners in a particular locale" (p. 2). They go on to argue that the success of school reform depends on a better understanding of "the interplay between research knowledge and local knowledge" (p. 2). The Goldenberg and Gallimore research indicates that research knowledge places no great demands on practitioners or policy makers, "no matter how valid or compelling such knowledge is to researchers" (p. 11). It was the local knowledge of the practitioners that determined whether new approaches to literacy and language acquisition, as established by research, would be adopted by the schools.

The contrasting of local and research knowledge is a good example of the distinction I have drawn between TK/P and TK/F, wherein local knowledge is a variety of the practical, while research knowledge is a variety of the formal. The local/research knowledge distinction also makes clear why I have avoided connecting formal with propositional, and practical with performance. In this study, the local knowledge was clearly propositional, though it may also have included performance knowledge. Though propositional in form, it was not research knowledge. Local knowledge can be propositional, explicitly stated, tested, and fully justified in a manner similar to any scientific claim; the sole difference is that its range of application is restricted to the context in which it was formed. In the Goldenberg and Gallimore context, local knowledge appears to be knowledge of particular instances, in contrast to general knowledge, which is knowledge of phenomena that share similar properties. 
Craft knowledge, like local knowledge, appears to reside in the TK/P category. Though teaching as a craft was explored in considerable depth by Tom (1984), he was more interested in developing an overall conception of the occupation of teaching than in teasing out the epistemic features of the concept of craft knowledge. That effort would await more recent treatments, such as those by Gaea Leinhardt $(1988,1990)$. Leinhardt's work, like other studies of practical knowledge, is grounded in a high degree of regard for teachers. However Leinhardt is careful not to regard all that they say or do as worthy of acknowledgement as wisdom or knowledge. From these twin perspectives of high regard and due caution, she formulates the notions of craft and situated knowledge.

Situated knowledge is "a form of expertise in which declarative knowledge is highly proceduralized and automatic and in which a highly efficient collection of heuristics exist for the solution of very specific problems in teaching" (Leinhardt, 1988 , p. 146). Leinhardt contends that situated knowledge can be contrasted with "context-free principled knowledge that is applicable or accessible in any circumstance.... Principled context-free knowledge is detached and generally true. It will always work and is thus very powerful..." (1988, p. 148). Situated knowledge competes with principled knowledge, such that when the two are side-by-side, "situated knowledge will be preferred in the particular situation in which it normally operates" (Leinhardt, 1988, p. 148). Note the similarity between this characteristic of situated knowledge and Goldenberg and Gallimore's contention that, unless specific steps are taken to address the possibility, local knowledge will almost always take precedence over research knowledge.

A few years after working out her concept of situated knowledge, Leinhardt turned to the problem of assessing teacher knowledge, arguing that any worthwhile assessment would have to take the craft knowledge of teachers into account. Though she did not, in this more current version, compare her earlier definition of situated knowledge with the later notion of craft knowledge, one senses a high degree of overlap. Craft knowledge includes "deep, sensitive, location-specific knowledge of teaching," as well as "fragmentary, superstitious and often inaccurate opinions" (Leinhardt, 1990, p. 18). In her view, the successful assessment of teacher knowledge and expertise calls for merging craft knowledge with theory and empirical research. Contentions such this one point to a fairly sharp distinction between craft or situated knowledge, on the one hand, and research knowledge on the other.

Another formulation of craft knowledge is offered by Grimmett and MacKinnon (1992). Their view departs from more descriptive characterizations, 
such as Leinhardt's, constituting instead a more prescriptive sense of craft in teaching. This normative sense of craft is clearly evident in the following formulation of the concept:

Craft knowledge of teaching is not substantive, subject matter knowledge .... It is a particular form of morally appropriate intelligent and sensible know-how that is constructed by teachers, holding progressive and radical educational beliefs, in the context of their lived experiences and work around issues of content-related and learner-focused pedagogy. (Grimmett \& MacKinnon, 1992, p. 396)

The authors identify teachers who possess such knowledge as crafty teachers, "in the dexterous, ingenious sense" of the term (p. 429).

There is obviously some variation in the literature on what we are to understand by the notions of craft and situated knowledge, ranging from Leinhardt's attempts to describe these forms of knowledge as they occur in teaching of various subjects to Grimmett and MacKinnon's conception of what we ought to understand when referencing the concept of craft knowledge. Another, more philosophical view of these concepts is offered by Robert Orton (in press).

Orton distinguishes between teacher knowledge that is situated and tacit. Situated knowledge is restricted in its range of application by place, time or context, much as Leinhardt contends. However, for Orton the fact that it is situated does not mean that it is incapable of discursive expression (the epistemologist would say that it can be articulated). Tacit knowledge, in contrast, cannot be articulated; it is "read off" or inferred from the performance of some skill or ability. Orton argues that situated knowledge does not present major challenges to epistemological justification, but tacit knowledge does. Because it can only be inferred from performance, tacit knowledge resists the kind of justification that would permit us to properly identify it as knowledge. Orton's analysis offers a number of provocative perspectives on the notions of situated and tacit knowledge. We will have occasion to reconsider some of his ideas at the end of part IV. Before moving on to that part, we will look one more time at the topic of justification.

\section{F. The justification of knowledge claims}

In their analysis of the cultures of teaching, Feiman-Nemser and Floden (1986, p. 515) write that it does not follow "that everything a teacher believes or is willing to act on merits the label knowledge, although that view has some support. Such a position makes the concept of knowledge as justified belief meaningless." Their point is well-taken, though there are reasons why the term 
know is preferred over related terms. Many philosophers regard the term knowledge a "purr" word; it feels so good to use and hear that we almost purr when doing so. It is also a concept with legitimating qualities; everyone has beliefs and opinions, but knowledge is something special, something that elevates one's thoughts and expressions beyond "mere" belief or opinion. Consider these comments by Elbaz on why she undertook her study of Sarah:

My intention was not simply to present for its own sake a picture of the teacher as a holder of knowledge. Rather I assumed that to change our view of the teacher is to open up new possibilities for action. Further, since knowledge is power, to see oneself as holding knowledge is also to see oneself differently in relation to existing sources of power. (Elbaz, 1983, p. 165)

One finds similar reflections in Clandinin, Shulman, Cochran-Smith and Lytle, and other researchers on teacher knowledge. While the sentiment behind such uses of the term knowledge may be most noble, they are ultimately destructive of their purpose when unaccompanied by ways of distinguishing between claims that have little or no epistemic status and those that have a great deal (Margaret Buchmann has made this point on a number of occasions; see, for example, Buchmann, 1984, 1986, 1987, 1993).

There are, as a result of this discussion, a number of possibilities for using the term 'knowledge' when referring to the mental states and activities of teachers::

1. It is indeed a type of knowledge, either formal or practical, and has considerable epistemic import.

2. It is simply a generic name to describe a broad range of mental states of teachers that arise from their training, experience and reflection, and has little if any epistemological import.

3. It is deliberate selection of a socially valued term, used with the primary intention of legitimating the insights, understandings, beliefs, and so forth that teachers possess.

Note that the third possibility does not mention anything about epistemological import. That is because epistemic import is not a consideration in this third conception. However, the only way version 3 succeeds is if it is somehow connected to version 1; i.e., that the notion of "teacher knowledge" has epistemological import and is not simply a group name designating the cognitions, mental states, or understandings of teachers. Though there is nothing intrinsically wrong with version 2 (it does, as noted earlier, follow one or more dictionary definitions of knowledge), it is unconnected to epistemic merit or status. That is, there is no basis in version 2 for deciding whether the knowledge 
of one teacher or researcher is better than, more trustworthy than, less troubled by error, more resistant to objection and criticism than the knowledge of any other teacher or researcher. To the extent a conception of knowledge does have epistemic merit, it will provide a basis for determining the strength, confidence, or trustworthiness of a claim to know something, whether that knowledge is propositional or performative, formal or practical.

To put these last few points another way, the claim that teachers know something is made either with or without epistemological import. If made without such import, it is uninteresting as an epistemological claim for its makes no assertions about knowledge, per se. Rather it is simply a taxonomic aid to the researcher, who seeks to group, as the dictionary states, "familiarity, awareness or understanding gained through experience or study." If such claims are made with the intent of having epistemic import, then there must be a way to justify the claims. Such justification requires some notion of standards that the claims must meet before they can properly be regarded as knowledge. The inquiry into standards takes us into a new arena of analysis, away from epistemology and to the nature of scientific inquiry.

\section{CONCEPTIONS OF SCIENCE IN THE STUDY OF TEACHER KNOWLEDGE}

A thoughtful examination of science in these times is far more challenging than it was a quarter century ago. Then we could have provided a fairly coherent presentation, being sensitive to the possibility of error only at the far margins of our descriptions. No such expository ease is available today, for now one must come to grips with radically disjunctive conceptions of science, including positivism and post-positivism, modernism and post-modernism, constructionist and deconstructionist. The consequence of taking such differing conceptions of science seriously is that it is increasingly difficult to speak of science as if it were the single undertaking or enterprise it was once believed to be. There appear, instead, to be multiple sciences, the rectitude of each a function of the undergirding theories and overarching values that characterize that view of science.

While perhaps exaggerated, this idea of multiple sciences is not far off the mark, particularly in those scientific activities employed to study and understand teaching and teachers. The proper approach to such study is contested, with what is often called folk psychology (or commonsense), on one side, and cognitive science (understood broadly to encompass the scientific study of human endeavors) on the other. Jerome Bruner $(1985,1986)$ has characterized this debate as two modes of thought or cognitive functioning. One he called the paradigmatic or logico-scientific mode; the other, the narrative mode. Bruner 
contends that the two modes are complementary, though irreducible. The paradigmatic mode "deals in general causes ... and makes use of procedures to assure verifiable reference and to test for empirical truth" (Bruner, 1986, p. 13). The narrative mode, on the other hand, leads to "good stories, gripping drama, believable (though not necessarily "true") historical accounts" (p. 13).

These two modes of thought appear to capture well what I have called the two types of knowledge about teaching. Formal knowledge fits the paradigmatic mode, while practical knowledge fits the narrative mode. Yet this particular characterization is problematic. If I correctly understand the folk psychology versus cognitive science debate, it is not that the former yields formal knowledge while the latter yields practical knowledge. It is rather that either, (a) one is correct and the other is in error, or (b) one is a more powerful, more useful and ameliorative account of human affairs than the other. As noted above, Bruner argues that the two are complementary, but irreducible. That is but one of the possible views of the differences between folk psychology and cognitive science. Another view is that they represent such radically different conceptions of human agency that only one could possibly be correct. Still another view is that both are worthy of consideration until such time as the state of our knowledge permits us to resolve the differences between them, keeping one and discarding the other, or accepting some new, dialectical offspring of the two. These views are variously represented in the work of Paul Churchland $(1984,1988)$, Daniel Dennett (1978, 1987, 1991), J. Christopher Maloney (1989), Joseph Margolis (1989), John Searle (1992), Stephen Stich (1983), as well as other contributors to this controversial topic.

\section{A. The Possibility of Two Sciences for the Study of Teaching}

The controversy over cognitive science and folk psychology is not likely to be understood if one is unaware of its background. In what I have called conventional social science (of which cognitive science, as used here and in the philosophical literature, is a variant), there has been an inclination towards a doctrine known as eliminative materialism, the notion that all mental concepts and mental language must be purged from any attempts to systematically understand human behavior. Thus talk of such things as reasons, intentions and motives would be eliminated from the discourse of the social scientist, whose interest would be a form of stimulus-response behaviorism, a cognitive science devoid of mental language, or a neuroscience that explained human behavior in relation to events or states in the brain. In contrast, folk psychology retains mental concepts; indeed, they are essential to the enterprise.

Those research programs that explore the practical knowledge of teachers, at least those examined in this review, clearly reject eliminative materialism. In the case of these programs, one could hardly make sense of knowledge-in-action, reflection-in-action, image, story, or narrative if mental language were prohibited 
from the discourse. Mental language is less apparent in, and sometimes missing from, studies of teaching that employ the methods of conventional science. Consideration of mental language in this context permits a further extension of the notion of practical knowledge. Practical knowledge in teaching is, as already noted, more than techn", more than knowing-how; it is a collective concept focussing on the mental lives of teachers, their thinking, ruminations, purposes, planning, desires, and a host of other features of what Dewey called "lived experience."

One may wonder whether there is or could be a science for the advancement of practical knowledge as there is a science for the advancement of formal knowledge. Bruner's split between folk psychology and cognitive science suggests that the doing of science is an enterprise of formal knowledge, and thus not a possibility for practical knowledge. Not everyone agrees with him, however. In delightful prose, the cultural anthropologist, Clifford Geertz (1983) describes what his colleagues face when they try to embrace a different way of thinking about their work:

It has thus dawned on social scientists that they did not need to be mimic physicists or closet humanists or to invent some new realm of being to serve as the object of their investigations. Instead they could proceed with their vocation, trying to discover order in collective life, and decide how what they were doing was connected to related enterprises when they managed to get some of it done; and many of them have taken an essentially hermeneutic--or, if that word frightens, conjuring up images of biblical zealots, literary humbugs, and Teutonic professors, an "interpretive"--approach to their task. Given the new genre dispersion, many have taken other approaches: structuralism, neo-positivism, neo-Marxism, micromicro descriptivism, macro-macro system building, and that curious combination of common sense and common nonsense, sociobiology. (p. 21)

For Geertz, "the penetration of the social sciences by the views of such philosophers as Heidegger, Wittgenstein, Gadamer, or Ricoeur, such critics as Burke, Frye, Jameson, or Fish, and such all-purpose subversives as Foucault, Habermas, Barthes, or Kuhn makes any simple return to a technological conception of those sciences highly improbable" $(1983$, p.4). Thus Geertz would, I believe, endorse the notion that it is possible to be engaged as a scientist in the study of human action, and make contributions to both formal and practical knowledge in the course of being so engaged. 
At issue here is whether there are adequate conceptions of science that permit the production of practical knowledge, in a way similar to our current understanding of how conventional science gives rise to formal knowledge. That is, are there systematic and dependable ways to go about discovering the practical knowledge that underlies human action? I take this question of whether there are scientific approaches to practical knowledge to be a part of what Cochran-Smith and Lytle are struggling with as they propound the notion of teacher research. Though they do not appear to exclude conventional social science from the work of teacher researchers, it seems clear that their reasons for believing that teachers are especially well positioned for research is that teachers possess in abundance what researchers do not, viz. practical knowledge.

Fortunately the development of the epistemological basis for practical argument need not await the resolution of this controversy. A science for the production of practical knowledge is not needed in order to make clear that practical knowledge is subject to standards of justification in the same way that propositional knowledge always has been . We are, I believe, misled by Ryle's view of knowing-how if we take him to mean that there is no need for justificatory standards in performance; that simply doing something is prima facie evidence that we know how, and further, that any demand that we explain or defend the performance would likely halt it because so much of what we do we cannot articulate. Ryle's contention may be an adequate rendering of simple performances within everyday life. It is not, however, an adequate analysis of professiona/ performance, of the performance of someone who is charged by a public to perform a special and specific set of tasks intended to bring about particular set of consequences. Teaching is just such a performance, one for which the epistemic merit of any claims to practical knowledge must be both clear and defensible; i.e., such claims are subject to evidentiary or justificatory demands in ways analogous to those of propositional knowledge.

It is, I believe, important to say what I am not arguing for here. I am not contending that claims to practical knowledge are subject to the same scrutiny as claims to formal knowledge; i.e., that they are to rigorously scrutinized as if they were candidates for formal (valid, generalizable) knowledge. Rather I am arguing that past attempts to equate practical knowledge with knowing-how, then ducking the matter of justification on the grounds that the "knowing-how" type of knowledge does not require justification (indeed, following Ryle, it logically could not be justified, at least not discursively), are mistaken. Performance knowledge, particularly when it falls within the domain of expert, specialist or professional practice, must meet evidentiary standards if it is to have epistemic merit. 
Denis Phillips, a philosopher of education who has long been involved in these matters, has expressed a similar point of view. Phillips (1980, 1981, 1985, $1988,1989,1992)$ has been a consistent defender of what might be called a "balanced epistemology" in the see-sawing controversies between positivist and post-positivist, modernist and post-modernist conceptions of social science. His position has been that even though scientific propositions cannot be proven to be true in any grand sense of the term, and even though our knowledge is fallible, these features do not permit us to make knowledge mean whatever we want it to mean. Consider his reaction to this very issue in a recent paper (Phillips, 1993, p. 5):

It is my growing concern that epistemological justifications are being replaced by "political" ones .... To take this position is not to deny that there is a political side to the issue of legitimation of the knowledge-claims of science; it simply is to underscore the point that there is also an epistemological side, one that might not have been totally undermined by the arguments of Kuhn, Feyerabend, and Rorty.

From here Phillips moves on to decry the lack of epistemological consideration in accounts of stories and narratives. "The fact that a story is credible," says Phillips (1993, p. 21), "tells us nothing--absolutely nothing--about whether it is true or false" (emphasis in original). He concludes his analysis of the place of knowledge in narrative with these words: "It is striking that on such an important matter--the status of narrative as a knowledge-bearing or explanation-giving genre--the supporting arguments turned out to be so scanty. From evidence internal to their writings I surmise that researchers who are pro-narrative have tended instead to have socio-political rather than epistemic grounds for their enthusiasm ..." (p. 29).

Phillips argues that the notions of verisimilitude and plausibility proposed by Bruner $(1986,1990)$ and Polkinghorne $(1983,1988)$ simply will not serve as adequate substitutes for the use of evidence and grounded reasons as justification for one's claims to knowledge--despite Bruner's discarding of all attempts at justification as "misplaced verification" (Bruner, 1986, p. 14). What is needed to deal with this problem is a more carefully constructed conception of justification, one that makes us more discriminating and discerning than has been typical for the appraisal and judgment of claims to practical or personal practical knowledge. Even with a clearer, more powerful conception of justification in the TK/P domain, we must deal with what, exactly, it is that is being justified. Is it a teacher's claim, a researcher's claim, or a researcher's claim about a teacher? These questions raise issues of how the knower participates in the construction of the known. To address these issues, a quite different approach is required. 


\section{B. The discourses of research and practice}

One way to differentiate the knowledge putatively generated by teachers and that generated by researchers is to distinguish between their respective discourses (the term discourse is used here in much the same way it is described by Cleo Cherryholmes, 1988). Let us call the discourse of practice Pdiscourse. P-discourse is the language of human action and activity. It is frequently framed in the mental language of intentions, desires, frustrations, aspirations, disappointments, surprises, and so forth. This discourse refers, for the most part, to what takes place in settings where teachers work. As such it pertains to the specific, situational, and particular. It is frequently characterized, in the words of Schön $(1983$, p. 39) by "complexity, uncertainty, instability, uniqueness, and value-conflict." P-discourse is most often expressed orally in contrast to discursively (see Ong, 1982). It often takes place without conscious reflection or deliberation on the discourse itself, though that is not a defining feature of P-discourse.

In contrast, the discourse of research is R-discourse. It is generally technical, abstract, and concerned, at least in part, with methods of inquiry. It is less the language of action and events, and more than language of how one studies action and events, and what one can learn from such study. Though considerations of value permeate this discourse, they are not matters of great debate within the discourse; indeed conscious efforts are usually made to eliminate value considerations from this discourse. A great deal of R-discourse takes place in written form; indeed there is a powerful belief among participants in R-discourse that its written form is more worthy of attention than its spoken form.

R-discourse is heavily structured by the key assumptions and theories to which its participants subscribe, as one can observe when comparing the more quantitative forms of inquiry, such as experimental, quasi-experimental, and correlational, to the more qualitative forms, such as interpretive, artistic, systematic, and theorydriven (these qualitative categories are taken from Mary Lee Smith, 1987).

By contrasting these two discourses, it is possible to raise a series of questions about teacher knowledge that could not be meaningfully addressed so long as our categories were limited to the practical and formal domains of teacher knowledge. These questions involve who is making knowledge claims about whom, and whether the type of claim varies as it crosses discourse boundaries. These questions highlight the notion of a locus of teacher knowledge. Consider, for example, the case of an R-discourse participant making a claim about a Pdiscourse participant's knowledge, as when a researcher contends that teachers have practical knowledge. One sees the emerging problems in the following hierarchy of discourse claims, where $R$ is the researcher, using R-discourse; $T$ is the teacher, using P-discourse; and $k$ is the precursor to a knowledge claim or an outright claim to know something: 
First level:

Second level:

Third level:

Fourth level:

Fifth level:

Sixth level:
$T$ expresses $k$.

$T$ knows that $k$.

$R$ expresses that $T$ expresses $k$.

$R$ knows that $T$ expresses $k$.

$R$ expresses that $T$ knows that $k$.

$R$ knows that $T$ knows that $k$.

The question that confronts us is at what level of discourse the researcher is speaking or writing when making statements about the practical knowledge of teachers. At the first level, $T$ expresses $k, T$ may be offering an explanation or description of an event, telling or writing a story, completing a diary entry, writing an essay, or any of a number of other forms of expression. We will suppose that at this first level, Ts discourse sets forth no claims to knowledge; rather $T$ is simply expressing a point of view, describing an occurrence, or considering some prior performance. In this form, there is no immediate obligation on $T$ to establish the warrant or justification for $k$. There are no obvious epistemological pitfalls here, but there are as soon as we move beyond the first level. The TK/P literature frequently leaves the reader in some doubt whether claims made about teacher knowledge are claims at levels 2, 4, 5 or 6 (level 3, like level 1, makes no knowledge claims). As one reads the actual case studies, researchers appear to be asserting that teachers said, did, observed, acted on, anguished over, wondered about, etc., without the researcher making explicit claims about what teachers know. As the researcher moves away from the actual raw data of the event, story or narrative, assertions at level 4, 5 or 6 become more common. What is not clear is whether these "upper" level assertions, as they appear in Rdiscourse, pertain to level one or two assertions, as these appear in P-discourse. Confusing? Perhaps rewording the problem will clarify the point.

When researchers assert that teachers have knowledge of something, are they making this assertion about something that teachers have merely expressed in the course of action, speech or writing, or about something that teachers themselves hold as knowledge? In the former case, researchers are attributing knowledge to teachers that teachers have not claimed to possess. In this case, it would seem that the researcher has two challenges. First, there is the matter of justifying the level two claim, $T$ knows that $k$, and then also justifying the level four or level six claims, $R$ knows that $T$ expresses/knows that $k$. In the absence of such justification, one must wonder about the legitimacy of the move to make level 4,5 or 6 assertions without first distinguishing level one from level two, and then, in the case of level two, establishing its warrant prior to addressing the question of warrant for $R$-discourse claims to know that the teacher knows.

One begins to get a sense of the magnitude of this problem when recalling claims about the local, contextual, situated, and even tacit aspect of practical knowledge. The more it is the case that any $K$ 's in P-discourse are contextually 
submerged, or comprehensible only to the extent that one is knowledgeable about the local culture, or dependent on being at a given place at a specific time, one's appreciation for the challenge of justification grows. It is already a fearsome task within P-discourse, where the discourse conditions are far more permissive, much less in R-discourse, where the demands for coherence and consistency, if not for methodological rigor, make the task of justification far more arduous.

These problems are not restricted to the practical knowledge contentions of those who search for answers to the question of what teachers know. They apply as well to those who seek answers to what knowledge is essential for teaching and who produces our knowledge about teaching. We are in need of Shulman's further assistance, for example, to determine whether his knowledge categories arise in $\mathrm{P}$ - or R-discourse, in which discourse he proposes to ground his claims about teacher knowledge, how he would resolve the inconsistencies between formal and practical conceptions of what teachers putatively know, and to identify more clearly the folk psychology or cognitive science parentage of the multiple categories of knowledge he has proposed. The teacher researcher proposals of Cochran-Smith and Lytle are similarly bedeviled by discourse problems. There proposals are ambiguous, for me at least, with regard to whether they would have P-discourse participants become proficient in Rdiscourse in order to assume the mantle of teacher researcher, or whether the teacher researcher is one who is content to establish level two claims, thereby warranting his or her practical knowledge without concern for any larger issues of validity or generalizability. Cochran-Smith and Lytle indicate that it is their intention that teachers study the phenomena in which they themselves are engaged; i.e., the phenomena of P-discourse. But they appear not to be any more successful than other proponents of practical knowledge in specifying how Pdiscourse is to be used to study P-discourse.

If the exquisite complexities of knowledge claiming and justifying in the domain of TK/P are not fully appreciated by the advocates of this genre of teacher research, an unfortunate permissiveness arises about what teachers may or may not know, how they know it, and what special kind of knowledge it is. Consider, for example, that in the teacher knowledge literature, the adjectives modifying the word knowledge are multiplying rather rapidly. It would be helpful to pause to consider the discourse levels that are traversed in positing new forms of teacher knowledge, as well as to consider anew what justificatory conditions must be met before the claims made in P- or R-discourse attain a level of epistemic status worthy of our considered attention.

The question now is whether efforts to remain in P-discourse, while formalizing one's understanding of and approach to it, may not also be regarded a scientific activity. That is, whether the domain of TK/P might not also be considered a kind of science, comparable in many respects to conventional 
science, but without acting on the mental language in ways that reduce, distort, reconstruct, or purge it as foundational to systematic inquiry. Geertz, as we have seen, is among those who believe that we can have a narrative or interpretive science. Bruner appears to hold the same belief. There are others who, while not necessarily embracing an interpretive or hermeneutic science, believe that the prevailing conception of science as naturalistic or conventional is far too restrictive and must be loosened. Feyerabend $(1975,1987)$ is among the more well known. $\mathrm{He}$ has railed against restrictive accounts of science for two decades. Another voice, less radical than Feyerabend's though still highly critical of current conceptions, is that of Mary Midgley (1989). She argues for a broader understanding of science, as well as a far more expansive concept of knowledge. Her views on the latter point are of great interest, and thus worth quoting at some length:

The meaning of the word 'know', like that of other words, is its use. This word is not the name of a peculiar mental state or process because, like very many other words, it is not a name at all. Its work is not the work of referring to or corresponding to some set object, but of helping people to distinguish between the more reliable and the less reliable parts of the world around them. In doing this, speakers offer their own guarantees, which are of course understood, like all human guarantees, to be fallible. Though it is our business as citizens and language-users to offer these guarantees carefully and responsibly, and therefore only to offer them when we do have reason to feel certain, it is not our business to be omniscient. The appearance of permanent, life-long confidence which seems to attach to some uses of words like 'know' is a superficial one, and does not even attach to all their uses. (p. 232).

Midgley would look with favor on many of the ways know is used in the $\mathrm{TK} / \mathrm{P}$ literature, but she clearly does not approve of its use in the absence of what she calls "guarantees." The question for some is whether these guarantees can be framed with sufficient clarity and sharpness of detail, and then held up to certain justificatory standards, that we might then refer to them and related activities as a science of practice, if you will, in contrast to the science of theory and law-like generalization. Such a suggestion is not at all absurd in the light of such claims as Schön's that there is an "epistemology of practice" which is indeed different and separate from the epistemology that characterizes conventional science.

This matter of a science of practice is one that has surfaced a number of times in this review, though I have not provided a definitive argument in its behalf. It requires a more inventive mind than mine. There may not be a great deal, however, that hangs on resolving the issue one way or the other. The 
question of whether P-discourse can be shaped into a science of its own may not be a very important one. P-discourse is the language of teaching, the mental language of intentions, reasons, feelings, desires, and all the human actions that accompany our mental states and events. The value of conventional science for teaching lies in its contributions to the epistemic status of assertions in Pdiscourse (those who are familiar with John Dewey's (1929) arguments in The Sources of a Science of Education will already be familiar with this claim). As such, conventional science plays a small role in the larger universe of teaching. As or more important to the epistemic quality of assertions in Pdiscourse is our capacity to do the very things that TK/P researchers are seeking to understand: Narrative, story, restorying, framing, reframing, reflecting, eliciting and reconstructing. These are activities of reason, and they are the heart of active engagement in P-discourse. When a conventional social science researcher or policy maker offers practitioners the evidence, the provocative concepts, the dispute-settling findings from conventional science, a word of appreciation, not obedience, is the proper response. Gage (1978) did not get it quite right. Teaching is a practice informed and helped by conventional science; it is not based on conventional science.

We began this part of the chapter noting how TK/P research programs challenge not only epistemological categories, but also scientific ones. There is yet another category that this research touches on, one not often mentioned or analyzed in either formal or practical research programs. It is the category of teacher reasoning. The relevance of this category to teacher research is twofold. First, it opens the various research programs to a different way of conceiving themselves, and to a literature that may be more productive and helpful than the epistemology literature. Second, it offers a different approach to the challenge of justifying practical knowledge, an approach that seems more consistent with the mental language in which P-discourse is so often framed. A consideration of teacher reasoning may offer a way to deal with the thorny problems of justification and epistemic status.

\section{ON TEACHER KNOWLEDGE AND TEACHER REASONING}

The issue of concern, as it has been throughout much of this chapter, is the defense of claims to know, made either by the practitioner or by the researcher about the practitioner. Within the context of contemporary epistemology and conventional social science, we have seen that the standards for the defense of knowledge claims is not nearly so harsh and problematic as some believe. Pristine, absolute, unfettered truth is neither required nor possible in the social sciences. With the softening of standards for truth and justification, many forms of conventional social science remain on relatively safe epistemological ground. However, conventional social science takes place by rules 
and procedures that often ignore, distort, reduce, reconstruct, or purge the mental language of those studied. That it does so is not, in my view, some terrible flaw in its character; it means simply that conventional social science is doing what it was designed to do. Its objective is not to capture the human drama or narrative unity of a person, group, culture, or the entire species. The objective is, instead, to understand this drama in ways that permit explanations, perhaps even predictions, that are at a level of abstraction and generalization sufficient to provide for the construction of robust theory and an expanding, increasingly sound body of knowledge.

There are those who argue that this approach to science fails to capture the essential qualities of being a person, such qualities as free will, purpose, feelings, doing the right thing at the right time, and a myriad of other aspects of the human condition. Advocates for this alternative approach appeal not only to our common sense, but to our ideals of the highest in human potential. Their appeals address much that we regard as noble about humankind, particularly the desire to be good persons and do good deeds. However, the advocates for this alternative approach are often at a disadvantage when pressed to provide the epistemological foundations for their endeavors. They lack the arsenal of epistemological devices that conventional science has accumulated since the time of Francis Bacon. Moreover, as advocates for an alternative science seek to build such an arsenal, it has proven difficult to achieve anything more than what some persons would regard as a poor imitation of conventional science. Conventional science has such a strong grip on our concepts of what counts as epistemic status, warrant and justification, that advocates for the alternative position appear imprisoned in a Whorfian universe of conventional science.

The situation, however, is not so bleak as this depiction suggests. It is possible to take a liberal stance on the matter of justification, such that there are a number of ways of warranting a knowledge claim. We have seen how evidence serves to justify formal knowledge claims, and also to warrant practical knowledge claims. Yet another way to justify that we know something is to offer good reasons for doing or believing it. Indeed this form of justification might be called the "good reasons" approach. Consider this example as a way of getting at the good reason approach. Suppose I observe a class that includes both learning disabled and non-handicapped children. As I observe the teacher, I note that his way of handling the class makes it very difficult to detect differences in learning abilities as one scans the students in this classroom. It seems that this teacher has a way of presenting materials, eliciting discussion, and engaging students in activities that provide opportunities for the strengths of all the children to be demonstrated at one time or another during the lesson. I think to myself that this teacher seems extremely proficient at handling a mainstreamed classroom. What I cannot ascertain from this one or even several more observations is whether this apparent expertise or artistry is in any way connected with the teacher's 
intentions and actions, such that I might accurately state, "This teacher knows how to promote high levels of student involvement in academic work in a mainstreamed classroom."

To explore my claim, I meet with the teacher, indicating to him that I noticed that he handled the learning disabled students in ways that made it difficult to detect their disability in relation to the non-disability students. I ask him what he does to accomplish this, and why he chose to do it this way. He responds that he has worked very hard on this feature of his teaching; he states that he is a strong believer in the moral principles that sustain mainstreaming, but really did not know how it would work in practice until he tried it. As this teacher continues to address my questions, he sets forth an account of what he does and why he does it. In other words, he provides reasons that make clear that it was his desire and intention to work with the class in the manner that I observed, that his procedures for doing so are the result of many trial-and-error efforts, readings, talking with other teachers, and talking with the students themselves about their perceptions of his teaching. In this example, the teacher is offering good reasons to explain his actions, reasons which, when taken together and arrayed in some coherent order, constitute a justification for the claim that this teacher knows how to promote student engagement in mainstreamed classrooms (examples of this kind of teacher reasoning may be found in Morgan, 1993, and Vasquez-Levy, 1993).

The reasoning of this teacher takes place in the folk or commensense language. It is P-discourse. As such, it can be extended and refined, but it cannot be swapped out of P-discourse and into R-discourse and still be reasoning about what and how one does something and whether the doing of it brings about one's hopes and desires for success of some sort. Reasoning of the sort I am referring to here is what Aristotle called phronesis, deliberative reflection of the relationship between means and ends. Jonsen and Toulmin (1988) explain the use of this concept in the time of Aristotle: "[phronesis] concerned situations the nature and complexity of which were unknown beforehand: it dealt with them not by merely reapplying predetermined generic techniques but by recognizing what combinations of actions are appropriate to complex or ambiguous situations" (p. 65).

Phronesis, or practical reasoning as I shall refer to it hereafter, is well suited to addressing some of the demands for epistemic warrant within Pdiscourse. The provision of reasons, when done well, makes action sensible to the actor and the observer. That is a minimal form of warrant for practical action. Such reasoning may also show that an action is, for example, the reasonable thing to do, the obvious thing to do, or the only thing one could do under the circumstances. Each of these is, I believe, a contribution to the epistemic merit of a practical knowledge claim. Practical reasoning may also address the moral 
aspects of action, indicating that it was fair, right, or the best of number of poor alternatives. As such, it permits us to consider the moral dimensions of teaching, dimensions that others (Goodland, Soder \& Sirotnik, 1990; Sockett, 1993; Strike \& Ternasky, 1993; Tom, 1984) argue are at the very heart of the enterprise of teaching. That it permits consideration of both epistemological and moral dimensions of teaching is a compelling reason for entertaining practical reasoning as an approach to the study of the practical knowledge of teachers.

Another advantage of practical reasoning is as a means for transforming the tacit quality of Ts knowing to a level of awareness that opens the possibility for reflective consideration. Consider a problem posed earlier, that of making a level six claim, $R$ knows that $T$ knows that $k$, when the level two claim, $T$ knows that $k$, is an instance of tacit knowing; i. e., it is the researcher who "detects" the teacher's "knowledge" of $k$, even though $T$ is unaware of $k$ as something he possesses in the form of knowledge or understanding. So long as this knowledge or understanding is tacit, it is unavailable to the teacher for further reflection. If the researcher probes, in a manner indicative of trust and mutual regard, the teacher's reasons for acting as he did, the performance "knowledge" that was heretofore tacit may reach a conscious level of awareness. Once aware of it, the teacher can deliberate or reflect upon it, and if it is found meritorious in that teacher's conception of his work, advance it as a reason to justify acting as he did.

The activities of framing and reframing described by Schön and prominently developed in the research of Munby and Russell (1992, Russell \& Munby, 1991; Russell, Munby, Spafford \& Johnston, 1988) and Erickson and MacKinnon (1991), as well as the practical argument work by Richardson and me (Richardson, in press/b; Fenstermacher and Richardson, 1993) are, among other things, examples of efforts to "surface" tacit understandings to a level of awareness that permits reflective or deliberative consideration. Viewed in this way, the tacit knowledge of teachers may not be so problematic as some (e.g., Orton) have thought. Once opened for reflective consideration, this understanding may contribute to the good reasons one has for doing what he did.

In the search for epistemic warrant for our beliefs and actions, the controversy between folk psychology and cognitive science can blur rather badly. We are, I believe, entitled to search for and use justifications wherever they may be found, so long as our use accords with the standards set by the epistemological context from which we pluck our evidence or warrant. Thus conventional, interpretive and other forms of research may all serve as possible sources of warrant for knowledge claims. In addition to these various forms of research, we may also employ more common or everyday conceptions of evidence to justify knowledge claims, as, for example, when we claim that heavy reading assignments combined with extensive testing often diminish student motivation to critically engage a topic of study, introducing as evidence the differences in 
perceived student performance between those occasions when heavy reading loads were assigned and a high number of tests were administered, and those occasions where lighter loads were assigned and fewer tests administered. Still other forms of justification are available as good reasons for our actions or claims, reasons that are arrayed in a relatively coherent and complete manner.

The point of this brief discussion of practical reasoning in teaching was to show how this concept may be thought of as another means for dealing with the justification of claims to practical knowledge. Among its special benefits are that it provides a way to deal with tacit claims to practical knowledge, and permits the introduction of the moral aspects of teaching into studies of teacher knowledge. Much work needs to be done to show precisely how practical knowledge and practical reasoning are related to one another. For the present, it is at least plausible to suggest that practical reasoning has a role in the justification of practical knowledge, and that this role makes possible considerations of practical knowledge that are not available when we restrict ourselves to traditional treatments of propositional knowledge and its justification as these appear in the epistemology literature.

With these thoughts on the uses of practical reasoning for the study of knowledge in teaching, the argument and analysis in this chapter come to an end. We turn to a recapitulation of the main points, as well as a reconsideration of the nature of knowledge in research on teaching.

\section{OUR KNOWLEDGE OF THE KNOWER AND THE KNOWN}

The research reviewed in this chapter clearly shows that there are different knowers and different knowns in the study of teaching. Researcher and teacher are different knowers, and the knowledge they generate as each goes about his or her work also differs. The discourse of these two occupational roles may be learned by the other, such that a researcher, employing the discourse of practice, may acquire practical knowledge of teaching, and a teacher, employing the discourse of research, may acquire formal knowledge of teaching. This last point is evident when we examine what research professors come to understand as they ponder their own teaching, as well as what elementary and secondary school teachers come to know about teaching in the course of their participation in conventional- science research studies.

Despite the clear case that many research studies in the area of teacher knowledge make for practical knowledge, there are serious epistemological problems in identifying as knowledge that which teachers believe, imagine, intuit, sense, and reflect upon. It is not that such mental activities may not lead to knowledge, rather it is that these mental events, once inferred or expressed, must 
first be subjected to assessment for their epistemic merit. Lacking epistemic merit, whatever understanding, belief or awareness is possessed by the teacher should not be identified as knowledge, at least not in the sense of implying epistemic merit (it might be so identified in the classifying or grouping sense of knowledge). Possessing epistemic merit, it may properly be considered knowledge.

That there is bona fide category of human knowledge called "practical knowledge" has been an occasion for some controversy among epistemologists and educational researchers. The issue for epistemologists is with the difficulty in establishing accepted epistemic standards for knowing-how or performance knowledge. Educational researchers who subscribe to the conventional science view of research have shown skepticism and even hostility towards the possibility of a knowledge type that is not only different from formal knowledge, but perhaps more powerful for understanding and advancing teaching than formal knowledge has been.

In this chapter I have tried to show that the concept of practical knowledge is a legitimate epistemological category, so long as we attach to it demands for justification or warrant in the same way such demands are attached to formal knowledge. Unless considerations of warrant or justification are attached to the concept of practical knowledge, this concept is without epistemic merit; it merely serves as a kind of grouping concept, or it appropriates the "purr" word knowledge as a means of making legitimate the labor of practitioners.

The call for justification in practical knowledge leads somewhat inevitably to the question of whether there is a science that yields practical knowledge analogous to the science that yields formal knowledge. In other words, is there a systematic way to go about establishing warrant or justification, that leads in turn to a codified body of accepted practical knowledge? I acknowledged that I do not know the answer to this question, though the line of thought that gives rise to it makes me uneasy. Concepts and methods of conventional science so dominate our thinking of what it means to be engaged in science that I fear the same troubling isomorphisms would connect conventional and alternative (practical) science as presently connect the physical and social sciences. Were this to happen, the practical--the situated, the time- and context-dependent, the mental language, the discourse of our work and practice--may be purged, distorted or reconstructed so that it no longer bears relationship or fidelity to what our practice is and to what ends we engage in it.

These reflections on two sciences for the study of teaching led to suggesting that we think in terms of two different discourses for the study of teaching. Each discourse is potentially knowledge-producing. In each discourse, when knowledge claims do arise, they are subject to assessment to ascertain 
their epistemic merit. The level of epistemic merit to which we should strive in practical discourse is that of "objectively reasonable," a sufficiently firm basis, in my view, to establish that we are in possession of practical knowledge. Lesser levels of epistemic merit are available, and may warrant claims to practical knowledge, though these must be used with considerable caution.

A somewhat different approach to the justification of practical knowledge is that of practical reasoning. Here the nature of justification shifts from the presentation of evidence, analogous to the uses of evidence in formal knowledge, to the development of "good reasons." Practical reasoning was introduced into the deliberations in this chapter for two reasons. First, it expands the concept of justification beyond the ways we are accustomed to thinking of it in the spheres of propositional knowledge and conventional science, providing a form of justification that is, in many cases, more appropriate to the nature of practical discourse. Second, the literature of practical reasoning in philosophy and education is different from that of straightforward epistemology. It is a literature that may hold more promise for our broadening and deepening our understanding of practical knowledge. The epistemological literature is not without value, as I hope this chapter shows, but its limits for expanding practical knowledge are quickly reached. These limits are particularly noticeable when we entertain what Sockett (1993) calls the "moral core" of teaching, a core that cannot be tapped by remaining in the epistemologist's realm (at least as epistemology is currently conceived). Hence the suggestion that those who are engaged in the study of Pdiscourse consider the potential of practical reasoning.

If all these considerations on the nature of knowledge in research on teaching are brought together, what do they imply for the future of this body of research? Different persons will have different answers; mine are as follows. Most importantly, there is indeed something called "practical knowledge." The research reviewed in this chapter shows great potential for taking our understanding of teachers and teaching to new heights and depths (depending on one's point of view about these things). Perhaps even more importantly, it holds the potential for changing and advancing the practice of teaching in ways never open to conventional social science. This potential exists because inquiry into practical knowledge remains embedded in the discourse of practice itself. Thus no "intermediary inventive mind," as William James (1892) would say, is needed to translate R-discourse into P-discourse (a shaky enterprise in the best of times).

If the potential of the notion of practical knowledge, or knowledge-inaction, or personal practical knowledge, or teacher knowledge is to be realized, all who would study it face an obligation to take seriously the fact that they are studying notions of knowledge, and as such, must work through matters of warrant and justification. Such notions are too lightly probed in the work of many researchers working within programs based on Schön, Connelly and Clandinin, 
and Cochran-Smith and Lytle. Somewhat more acknowledgement is offered in the program of research based on Shulman, but this acknowledgement is confounded by the extent that conceptions of the practical appear to be driven by conceptions of the formal, as well as by the ever-shifting descriptive and normative orientations in Shulman's own work.

Connelly and Clandinin's work is perhaps most explicitly focussed on the concept of practical knowledge, as an epistemological idea, yet exhibits the least attention to warrant and justification of any of the research reviewed here. The work of Munby, Russell, Grimmett, Erickson and MacKinnon (all within the Schön strand) is highly attentive to the fact that it is investigating knowledge of a particular kind, though it has yet to deal with the fragility of inferences by the researcher that the teacher knows this or that as a result of action or reflection on that action. Moreover, the Schön strand researchers have yet to come to grips with the difference between the justification of their own inferences of teacher knowledge and the justification of what the teacher knows (a problem of levels of discourse).

The work of Cochran-Smith and Lytle raises some of the most intriguing questions about the discourse of school teachers and university-based researchers. Whether it will also provide answers to these questions is contingent, I believe, on their sensitivity to epistemological distinctions and differences in discourse between researcher and practitioner. As I read this work, I am puzzled about whether they argue for or seek one or two sciences for the study of teaching, and how they will resolve issues of discourse level, justification, and moral reasoning in their program for teacher research.

In raising these questions and cautions about the research programs reviewed here, I in no way wish to impugn their value to the field or their potential to influence the next wave of research on teaching. They have succeeded in establishing a form of knowledge different from that provided by conventional social science, an achievement of heroic proportion. They have succeeded in providing a conception of teachers and their teaching that is morally congruent with our very best conceptions of the nature and purpose of education. Finally, they have raised questions so provocative and exciting that they spark profound dialogue and discussion among students of teaching. These are extraordinary accomplishments. My hope is that this review will make a modest contribution to their becoming even more extraordinary.

This chapter comes to an end with an idea from a philosopher who has been cited a number of times in this review. Keith Lehrer has developed a notion he calls metamind. It is a concept that captures well what I believe teacher knowledge research hopes to achieve. For Lehrer $(1990$, p. 2) a metamental operation is "a thought about a thought, about a feeling, or about an emotion." 
This operation, he argues, must be intentional; i.e., we must consciously set about to do it. He states that

a thought causing a thought is not a metamental operation. A thought about a thought is. Intentionality is not causality. So a being might have thoughts that caused other thoughts without having metamental operations or the capacity for metamental operations. Such a being would lack human freedom, rationality, consensus, knowledge and even general conceptions. (p. 2)

One way to view research of either type, formal or practical, is that its purpose is to engage the metamental operations of persons. Though it smacks of the language of cognitive science, consider Lehrer's description of how metamental activity takes place:

The mind contains an input system that receives information from the outside world and provides us with a representation of that information as output. That output is the input for a higher-order system, a central system, that evaluates the lower-level information represented by the input system. The evaluation may result in acceptance of the lower-level information or in rejection of that information. The output of such evaluation--acceptance, for example--is a functional state that plays a special role in memory, inference, and action. (Lehrer, 1990b, p. 2)

As I ponder the notion of metamind, it suggests that the critical objective of teacher knowledge research is not for researchers to know what teachers know, but for teachers to know what they know. It is, as I believe Cochtran-Smith and Lytle would agree, for teachers to be knowers of the known. Both conventional social science and the alternatives can assist in attaining this objective. If however, the science we employ seeks simply to know what is known by others, it is neither a very powerful nor very useful science. Conventional social science has often found itself in just this situation. At times the advocates for folk psychology seem to come close to riding their methodological horses into the same box canyon, or they just get frustrated and toss the whole epistemological apparatus. That is not a helpful course for teachers, or education in general. There is much merit in believing that teachers know a great deal, and in seeking to learn what they know, but that merit is corrupted and demeaned when it is implied that this knowledge is not subject to justification, or that it cannot or should not be justified. The challenge for teacher knowledge research is not simply one of showing us that teachers think, believe, or have opinions, but that they know. And even more important, that they know that they know. 


\section{References}

Alexander, P., Schallert, D., \& Hare, V. (1991). Coming to terms: How researchers in learning and literacy talk about knowledge. Review of Educational Research, 61(3), 315-343.

Anscombe, G. (1963). Intention (Second Edition). Ithica, N.Y.: Cornell University Press.

Ayer, A. (1956). The problem of knowledge. Harmondsworth, Middlesex: Penguin Books.

Belenky, M., Clinchy, B., Goldberger, N., \& Tarule, J. (1986). Women's ways of knowing: The development of self, voice, and mind. New York: Basic Bdousiner, D. C. (1987). Knowledge is power: A talk to teachers about a revolution in the teaching porfession. In D. C. Berliner \& B. V. Rosenshine (Eds.), Talks to teachers (pp. 3-36). NY: Random House.

Bruner, J. (1985). Narrative and paradigmatic modes of thought. In E. Eisner (Eds.), Learning and teaching the ways of knowing (pp. 97115). Eighty-fourth Yearbook of the National Society for the Study of Education. Chicago: University of Chicago Press.

Bruner, J. (1986). Actual minds, possible worlds. Cambridge: Harvard University Press.

Bruner, J. (1990). Acts of meaning. Cambridge: Harvard University Press.

Buchmann, M. (1984). The use of research knowledge in teacher education and teaching. American Journal of Education, 92(4), 421-439.

Buchmann, M. (1986). Role over person: Morality and authenticity in teaching. Teachers College Record, (87)4, 529-543.

Buchmann, M. (1987). Teaching knowledge: The lights that teachers live by. Oxford Review of Education, 13(2), 151-164.

Buchmann, M. (1993), Teacher thinking, teacher change, and the "capricious seamstress"--memory. In H.A. Alexander, (Ed.), Philosophy of Education, 1992 (Proceedings of the annual meeting of the Philosophy of Education Society, pp. 290-299), Urbana III: Philosophy of Education.

Carter, K. (1990). Teachers' knowledge and learning to teach. In W. Houston (Eds.), Handbook of research on teacher education (pp. 291310). New York: Macmillan.

Carter, K. (1993). The place of story in the study of teaching and teacher education. Educational Researcher, 22(1), 5-18.

Cherryholmes, C. H. (1988). Power and criticism: Poststructural investigations in education. NY, NY: Teachers College Press. 
Chisholm, R. (1989). Theory of knowledge [Third edition]. Englewood Cliffs, N.J.: Prentice Hall.

Churchland, P. M. (1984, 1988). Matter and consciousness (Rev. ed., 1988). Cambridge, MA: MIT Press.

Clandinin, D. J. (1986). Classroom practice: Teacher images in action. London: Falmer Press.

Clandinin, D. J. (1992). Narrative and story in teacher education. In T. Russell and H. Munby (Eds.), Teachers and teaching: From classroom to reflection (pp.124-137). London: Falmer Press.

Clandinin, D.J., \& Connelly, F. M. (1987). Teachers' personal knowledge: What counts as personal in studies of the personal. Journal of Curriculum Studies, 196), 487-500.

Clandinin, D.J., \& Connelly, F. M. (1991). Narrative and story in practice and research. In D. Schön (Ed.), The reflective turn: Case studies in and on educational practice (pp. 258-281). New York: Teachers College Press.

Clift, R. T., Houston, W. R., \& Pugach, M. C. (Eds.) (1990). Encouraging reflective practice in education. NY: Teachers College Press.

Cochran-Smith, M., \& Lytle, S. (1990). Research on teaching and teacher research: The issues that divide. Educational Researcher, 19(2), 211.

Cochran-Smith, M., \& Lytle, S. (1993). Inside outside: Teacher research and knowledge. New York: Teachers College Press.

Code, L. (1991). What can she know? Feminist theory and the construction of knowledge. Ithaca, NY: Cornell University Press.

Connelly, F.M., \& Clandinin, D.J. (1985). Personal practical knowledge and the modes of knowing: Relevance for teaching and learning. In E. Eisner (Eds.), Learning and teaching the ways of knowing (pp. 174-198). Eighty-fourth Yearbook of the National Society for the Study of Education.

Connelly, F. M., \& Clandinin, D. J. (1988). Teachers as curriculum planners. NY: Teachers College.

Connelly, F. M., \& Clandinin, D. J. (1990). Stories of experience and narrative inquiry. Educational Researcher, 19(5), 2-14.

Dennett, D. C. (1978). Brainstorms. Montgomery, VT: Bradford Books.

Dennett, D. C. (1987). The intentional stance. Cambridge, MA: MIT Press

Dennett, D. C. (1991). Consciousness explained. Boston: Little, Brown \& Co.

Dewey, J. (1929). The sources of a science of education. NY: Liveright. 
Dunkin, M. (Ed.). (1987). The international encyclopedia of teaching and teacher education. New York: Pergamon.

Elbaz, F. L. (1983). Teacher thinking: A study of practical knowledge. London: Croom Helm.

Elbaz, F. (1991). Research on teacher's knowledge: The evolution of a discourse. Journal of Curriculum Studies, 23(1), 1-19.

Erickson, G. L. \& MacKinnon, A. M. (1991). Seeing classrooms in new ways: On becoming a science teacher. In D. A. Schön (Ed.), The reflective turn (pp. 15-36). NY: Teachers College Press.

Feiman-Nemser, S., \& Floden, R. (1986). The cultures of teaching. In M. Wittrock (Ed.), Handbook of research on teaching (3rd edition, pp. 505526). NY: Macmillan.

Fenstermacher, G. D. (1986). Philosophy of research on teaching: Three aspects. In M. C. Wittrock (Ed.), Handbook of research on teaching (3rd ed.) (pp. 37-49). NY, NY: Macmillan.

Fenstermacher, G. (1987). Prologue to my critics, and A reply to my critics. Educational Theory, 374), 357-360; 413-421.

Fenstermacher, G. D. (1988). The place of science and epistemology in Schön's conception of reflective practice. In P. P. Grimmett \& G. L. Erickson (Eds.), Reflection in teacher education (pp. 39-46). NY, NY: Teachers College Press.

Fenstermacher, G., \& Richardson, V. (1993). The elicitation and reconstruction of practical arguments in teaching. Journal of Curriculum Studies, 25(2), 101-114.

Feyerabend, P. (1975). Against method (Verso edition of 1978). London: Verso.

Feyerabend, P. (1987). Farewell to reason. London: Verso.

Gage, N. (1978). The scientific basis of the art of teaching. New York: Teachers College Press.

Gage, N. (1985). Hard gains in the soft sciences: The case of pedagogy. Bloomington, IN: Phi Delta Kappa.

Gardner, w. (1989). Preface. In M. C. Reynolds (Ed.), Knowledge Base for the Beginning Teacher (pp. ix-xii). Oxford, England: Pergamon Press.

Geertz, C. (1983). Local knowledge. NY: Basic Books.

Gettier, E., Jr. (1963). Is justified true belief knowledge? Analysis, 23, 121123.

Gilligan, C. (1982). In a different voice: Psychological theory and women's development. Cambridge, MA: Harvard University Press. 
Goldenberg, C., \& Gallimore, R. (1991). Local knowledge, research knowledge, and educational change: A case study of early Spanish reading improvement. Educational Researcher, 20(8), 2-14.

Goodlad, J.I., Soder, R. \& Sirotnik, K. A. (Eds.) (1990). The moral dimensions of teaching. San Francisco: Jossey-Bass.

Green, T. F. (1971). The activities of teaching. NY: McGraw-Hill.

Grimmett, P. P. \& Chehan, E. P. (1990). Barry: A case of teacher reflection in clinical supervision. Journal of Curriculum and Supervision, $\underline{5}(3), 214-235$.

Grimmett, P., \& Mackinnon, A. (1992). Craft knowledge and the education of teachers. In G. Grant (Ed.), Review of Research in Education: 18 (pp. 385-456). Washington, DC: American Educational Research Association.

Grossman, P. L. (in press). Teacher knowledge. In T. Husen \& T. N. Postlethwaite (Eds.), The international encyclopedia of education (2nd ed.). London: Pergamon.

Grossman, P. (1990). The making of a teacher: Teacher knowledge and teacher education. New York: Teachers College Press.

Grossman, P. L., Wilson, S. M., \& Shulman, L. S. (1989). Teachers of sustance: Subject matter knowledge for teaching. In M. Reynolds (Ed.), Knowledge base for the beginning teacher (pp. 23-36). Oxford, England: Pergamon Press.

Hamlyn, D. (1967). History of epistemology. In P. Edwards (Eds.), The Encyclopedia of Philosophy, Vol. 3 (pp. 8-38). New York: Macmillan.

James, W. (1892/1958). Talks to teachers. NY, NY: W. W. Norton \& Company.

Johnson, M. (1987). The body in the mind: The bodily basis of meaning, imagination, and reason. Chicago, IL: University of Chicago Press.

Johnson, M. (1989). Embodied knowledge. Curriculum Inquiry, 194), 361 377.

Johnson, O. A. (1980). The standard definition. In P. A. French, T. E. Uehling, Jr., \& H. K. Weftstein (Eds.), Midwest studies in philosophy V: Studies in epstemology (pp. 113-126). Minneapolis, MN: University of Minnesota Press.

Jonsen, A. R., \& Toulmin, S. (1988). The abuse of casuistry. Berkeley, CA: University of California Press. 
Kagan, D. (1990). Ways of evaluating teacher cognition: Inferences concerning the Goldilocks principle. Review of Educational Research, 60(3), 419469.

Kilbourn, B. (1987). The nature of data for reflecting on teaching situations. Educational Theory, 37(4), 377-382.

Lakatos, I. (1970). Falsification and the methodology of scientific research programmes. In I. Lakatos \& A. Musgrave (Eds.), Criticism and the grwoth of knowledge (pp. 91-195). Cambridge, England: Cambridge University Press.

Lehrer, K. (1990a). Theory of knowledge. Boulder, CO: Westview Press.

Lehrer, K. (1990b). Metamind. Oxford: Clarendon Press.

Leinhardt, G. (1988). Situated knowledge and expertise in teaching. In J. Calderhead (Eds.), Teachers' professional learning (pp. 146-168). Basingstoke: Falmer.

Leinhardt, G. (1990). Capturing craft knowledge in teaching. Educational Researcher, 19(2), 18-25.

Maclntyre, A. (1984). After virtue. A study in moral theory (Second edition). Notre Dame, IN: University of Notre Dame Press.

Maloney, J. C. (1989). The mundane matter of the mental language. Cambridge, England: Cambridge University Press.

Margolis, J. (1989). Texts without referents. Oxford, England: Basil Blackwell.

Midgley, M. (1989). Wisodom, information and wonder. London: Routledge.

Morgan, B. A. (1993). Practical rationality: A self-investigation. Curriculum Inquiry, 25(2), 115-124.

Munby, H. (1987). The dubious place of practical argument and scientific knowledge in the thinking of teachers. Educational Theory, 37(4), 361-368.

Munby, H., \& Russell, T. (1992). Transforming chemistry research into chemistry teaching: The complexities of adopting new frames for experience. In T. Russell \& H. Munby (Eds.), Teachers and teaching: From classroom to reflection (pp. 90-123). London: Falmer.

Nelson, B. (1992). Teachers' special knowledge. Educational Researcher, 21(9), 32-33.

Noel, J. (1993). Intentionality in research on teaching. Educational Theory, $\underline{43}(2), 123-145$.

Ong, W. J. (1982). Orality and literacy. London: Methuen. 
Orton, R.E. (In Press), Two problems with teacher knowledge. In Audrey Thompson, Ed., Philosophy of Education, 1993 (Proceedings of the forty-eighth annual meeting of the Philosophy of Education Society). Urbana, IL: Philosophy of Education Society.

Pappas, G., \& Swain, M. (1978). Essays on knowledge and justification. Ithaca, NY: Cornell University Press.

Pears, D. (1971). What is knowledge? New York: Harper \& Row.

Phillips, D. C. (1980). What do the researcher and the practitioner have to offer each other? Educational Researcher, 9(11), 17-20,24.

Phillips, D. C. (1981). Post-Kuhnian reflections on educational research. In J. F. Soltis (Ed.), Philosophy and education: Eightieth yearbook of the National Society for the Study of Education (pp. 237-261). Chicago, IL: University of Chicago Press.

Phillips, D. C. (1985). On what scientists know and how they know it. In E. Eisner (Ed.), Learning and the ways of knowing (Eighty-fourth yearbook of the National Society for the Study of Education, pp. 37-59). Chicago: University of Chicago Press.

Phillips, D. C. (1988). On teacher knowledge: A skeptical dialogue. Educational Theory, 38(4), 457-466.

Phillips, D. C. (1989). Response to Schrag, or, he who laughs last. Educational Theory, 39(3), 271-272.

Phillips, D. C. (1992). The social scientist's bestiary. Oxford: Pergamon.

Phillips, D. C. (1993, April). Telling it straight: Issues in assessing narrative research. A paper presented at the Annual Conference of the Philosophy of Education Society of Great Britain, Oxford, England.

Polanyi, M. (1964). Personal knowledge: Towards a post-critical philosophy. New York: Harper \& Row.

Polanyi, M. (1966). The tacit dimension. Garden City, NY: Doubleday \& Co.

Polkinghorne, D. (1983). Methodology for the social sciences. Albany, NY: State University of New York Press.

Polkinghorne, D. E. (1988). Narrative knowing and the human sciences. Albany, NY: State University of New York Press.

Quinton, A. (1967). Knowledge and belief. In P. Edwards (Eds.), Encyclopedia of Philosophy, Vol. 4 (pp. 345-352). New York: Macmillan.

Reynolds, M. (Ed.). (1989). Knowledge base for the beginning teacher. New York: Pergamon.

Richardson. V. (in press/a). Conducting research on practice. Educational Researcher. 
Richardson, V. (in press/b). The consideration of beliefs in staff development. In V. Richardson (Ed.), A theory of teacher change and the practice of staff development: A case in reading instruction. New York: Teachers College Press.

Russell, T. L. (1987). Research, practical knowledge, and the conduct of teacher education. Educational Theory, 37(4), 369-375.

Russell, T. \& Munby, H. (1991). Reframing: The role of epxerience in developing teacher's professional knowledge. In D. A. Schön (Ed.), The reflective turn (pp. 164-187). NY: Teachers College.

Russell, T., \& Munby, H. (Eds.), (1992). Teachers and teaching: From classroom to reflection. London: Falmer Press.

Russell, T., Munby, H., Spafford, C., \& Johnston, P. (1988). Learning the professional knowledge of teaching. In P. Grimmett \& G. Erickson (Eds.), Reflection in teacher education (pp. 67-90). New York: Teachers College Press.

Ryle, G. (1949). The concept of mind. New York: Barnes \& Noble.

Scheffler, I. (1965). Conditions of knowledge: An introduction to epistemology and education. Chicago: Scott, Foresman \& Company.

Schön, D. (1983). The reflective practitioner. New York: Basic Books.

Schön, D. A. (1987). Educating the reflective practitioner. San Francisco: Jossey-Bass.

Schön, D. A. (1991). The reflective turn: Case studies in an on educational practice. NY: Teachers College.

Searle, J. R. (1992). The rediscovery of mind. Cambridge, MA: MIT Press.

Shope, R. (1983). The analysis of knowing: A decade of research. Princeton, N.J.: Princeton University Press.

Shulman, L. (1984). The practical and the eclectic: A deliberation on teaching and educational research. Curriculum Inquiry, 14(2), 183-200.

Shulman, L. (1986a). Paradigms and research programs in the study of teaching [3rd edition]. In M. Wittrock (Eds.), Handbook of research on teaching (pp. 3-36). New York: Macmillan.

Shulman, L. (1986b). Those who understand: Knowledge growth in teaching. Educational Researcher, 15(7), 4-14.

Shulman, L. S. (1987a). Knowledge and teaching: Foundations of the new reform. Harvard Educational Review, 57(1), 1-22.

Shulman, L. S. (1987b). The wisdom of practice. In D. Berliner \& B. Rosenshine (Eds.), Talks to teachers: A festschrift for N.L. Gage (pp. 369386). New York: Random House. 
Shulman, L. (1989, June). Toward a pedagogy of substance. AAHE Bulletin, pp. 8-13.

Shulman, L. (1992). Toward a pedagogy of cases. In J. Shulman (Eds.), Case methods in teacher education (pp. 1-29). New York: Teachers College Press.

Smith, M. L. (1987). Publishing qualitative research. American Educational Research Journal, 24(2), 173-183.

Smyth, W. I. (1987). A rationale for teachers' critical pedagogy: $A$ handbook. Victoria, Australia: Deakin University Press.

Sockett, H. (1993). The moral base for teacher professionalism. NY: Teachers College.

Stich, S. P. (1983). From folk psychology to cognitive science. Cambridge, MA: MIT Press.

Strike, K. A., \& Ternasky, P. L. (Eds.), (1993). Ethics for professionals in education. NY: Teachers College Press.

Tom, A. R. (1984). Teaching as a moral craft. NY: Longman.

Tom, A., \& Valli, L. (1986). Professional knowledge for teachers. In W. Houston (Eds.), Handbook of Research on teacher education (pp. 373392). New York: Macmillan.

Van Doren, C. (1991). A history of knowledge: Past, present and future. New York: Ballantine Books.

Vasquez-Levy, D. (1993). The use of practical arguments in clarifying and changing practical reasoning and classroom practices: two cases. Curriculum Inquiry, 25(2), 125-143.

Willinsky, J. (1989). Getting personal and practical with personal practical knowledge. Curriculum Inquiry. 19(3). 247-264.

Wilson, S., Shulman, L., \& Richert, A. (1987). ' 150 different ways' of knowing: Representations of knowledge in teaching. In J. Calderhead (Ed.), Exploring teachers' thinking (pp. 104-124). London: Cassell.

Wittrock, M. (Ed.). (1986). Handbook of research on teaching [Third edition]. New York: Macmillan.

c:|wpdocs|ms|rre|rre90ss / November 8, 1993 / reset for web October 18, 2001 